\title{
Production Cost Modeling for High Levels of Photovoltaics Penetration
}

P. Denholm, R. Margolis, and J. Milford

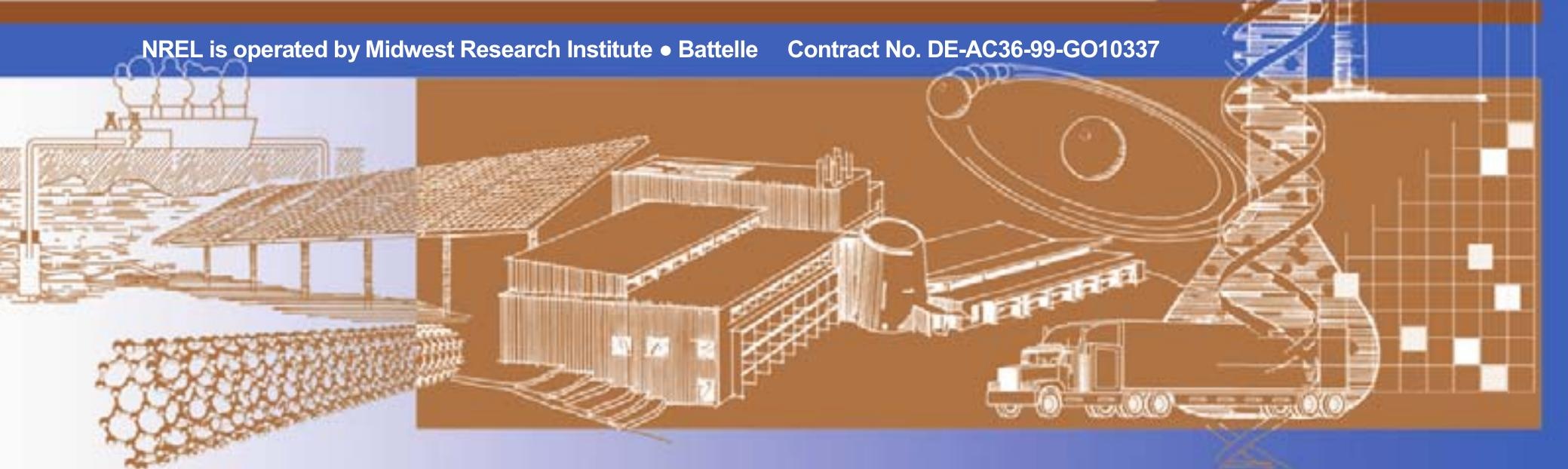




\section{Production Cost Modeling for High Levels of Photovoltaics Penetration}

\author{
P. Denholm, R. Margolis, and J. Milford
}

Prepared under Task No. PVB7.6401
Technical Report NREL/TP-581-42305

February 2008

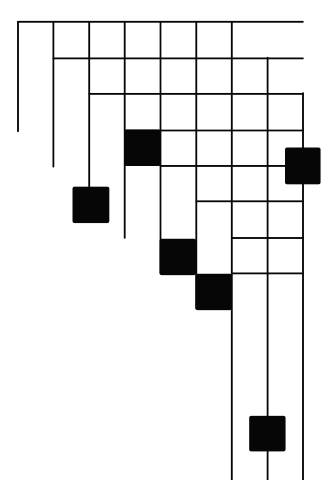




\section{NOTICE}

This report was prepared as an account of work sponsored by an agency of the United States government. Neither the United States government nor any agency thereof, nor any of their employees, makes any warranty, express or implied, or assumes any legal liability or responsibility for the accuracy, completeness, or usefulness of any information, apparatus, product, or process disclosed, or represents that its use would not infringe privately owned rights. Reference herein to any specific commercial product, process, or service by trade name, trademark, manufacturer, or otherwise does not necessarily constitute or imply its endorsement, recommendation, or favoring by the United States government or any agency thereof. The views and opinions of authors expressed herein do not necessarily state or reflect those of the United States government or any agency thereof.

Available electronically at http://www.osti.gov/bridge

Available for a processing fee to U.S. Department of Energy and its contractors, in paper, from:

U.S. Department of Energy

Office of Scientific and Technical Information

P.O. Box 62

Oak Ridge, TN 37831-0062

phone: 865.576 .8401

fax: 865.576 .5728

email: mailto:reports@adonis.osti.gov

Available for sale to the public, in paper, from:

U.S. Department of Commerce

National Technical Information Service

5285 Port Royal Road

Springfield, VA 22161

phone: 800.553.6847

fax: 703.605.6900

email: orders@ntis.fedworld.gov

online ordering: http://www.ntis.gov/ordering.htm 


\section{Preface}

Now is the time to plan for the integration of significant quantities of distributed renewable energy into the electricity grid. Concerns about climate change, the adoption of state-level renewable portfolio standards and incentives, and accelerated cost reductions are driving steep growth in U.S. renewable energy technologies. The number of distributed solar photovoltaic (PV) installations, in particular, is growing rapidly. As distributed PV and other renewable energy technologies mature, they can provide a significant share of our nation's electricity demand. However, as their market share grows, concerns about potential impacts on the stability and operation of the electricity grid may create barriers to their future expansion.

To facilitate more extensive adoption of renewable distributed electric generation, the U.S. Department of Energy launched the Renewable Systems Interconnection (RSI) study during the spring of 2007. This study addresses the technical and analytical challenges that must be addressed to enable high penetration levels of distributed renewable energy technologies. Because integration-related issues at the distribution system are likely to emerge first for PV technology, the RSI study focuses on this area. A key goal of the RSI study is to identify the research and development needed to build the foundation for a high-penetration renewable energy future while enhancing the operation of the electricity grid.

The RSI study consists of 15 reports that address a variety of issues related to distributed systems technology development; advanced distribution systems integration; system-level tests and demonstrations; technical and market analysis; resource assessment; and codes, standards, and regulatory implementation. The RSI reports are:

- Renewable Systems Interconnection: Executive Summary

- Distributed Photovoltaic Systems Design and Technology Requirements

- Advanced Grid Planning and Operation

- Utility Models, Analysis, and Simulation Tools

- Cyber Security Analysis

- Power System Planning: Emerging Practices Suitable for Evaluating the Impact of High-Penetration Photovoltaics

- Distribution System Voltage Performance Analysis for High-Penetration Photovoltaics

- Enhanced Reliability of Photovoltaic Systems with Energy Storage and Controls

- Transmission System Performance Analysis for High-Penetration Photovoltaics

- Solar Resource Assessment

- Test and Demonstration Program Definition

- Photovoltaics Value Analysis

- Photovoltaics Business Models 
- Production Cost Modeling for High Levels of Photovoltaic Penetration

- Rooftop Photovoltaics Market Penetration Scenarios.

Addressing grid-integration issues is a necessary prerequisite for the long-term viability of the distributed renewable energy industry, in general, and the distributed PV industry, in particular. The RSI study is one step on this path. The Department of Energy is also working with stakeholders to develop a research and development plan aimed at making this vision a reality. 


\section{Executive Summary}

Solar PV is being deployed in part to reduce dependence on fossil fuels for electricity use and associated emissions of greenhouse gases and criteria pollutants such as nitrous oxides $\left(\mathrm{NO}_{\mathrm{x}}\right)$ and sulfur dioxide $\left(\mathrm{SO}_{2}\right)$. Given the time-varying output of photovoltaic (PV) equipment, and the diverse set of electric generators in the power plant fleet, there is considerable uncertainty as to the actual benefits of PV in various regions.

This report uses a production cost modeling approach to evaluate the large scale interaction of solar electricity technologies with the existing and possible future grid, with a focus on displaced generation capacity, fuel saved, and emissions avoided by deploying varying levels of solar electric generation. This study established a PV penetration scenario in several regions in the western U.S. grid (the Western Electricity Coordinating Council - WECC) and simulates the response of the power plant fleet. While focusing on avoided fuels and emissions that result from PV deployment, this analysis also identifies areas of future research to increase understanding of benefits and impacts of large-scale PV deployment.

The simulations evaluated a series of PV penetrations in which $1 \%$ to $10 \%$ of the entire western interconnect's annual electrical energy is derived from PV. The PV is distributed based on an assumed market penetration scenario with higher penetration in the Southwest and California and lower penetration in the Northeastern part of the region.

Figure E-1 illustrates the simulated impact of the deployment of PV during a single day in California under five penetration scenarios. On this day, the deployment of PV reduces the generation primarily from natural gas-fired power plants (labeled CC for combinedcycle and CT for combustion turbine). 


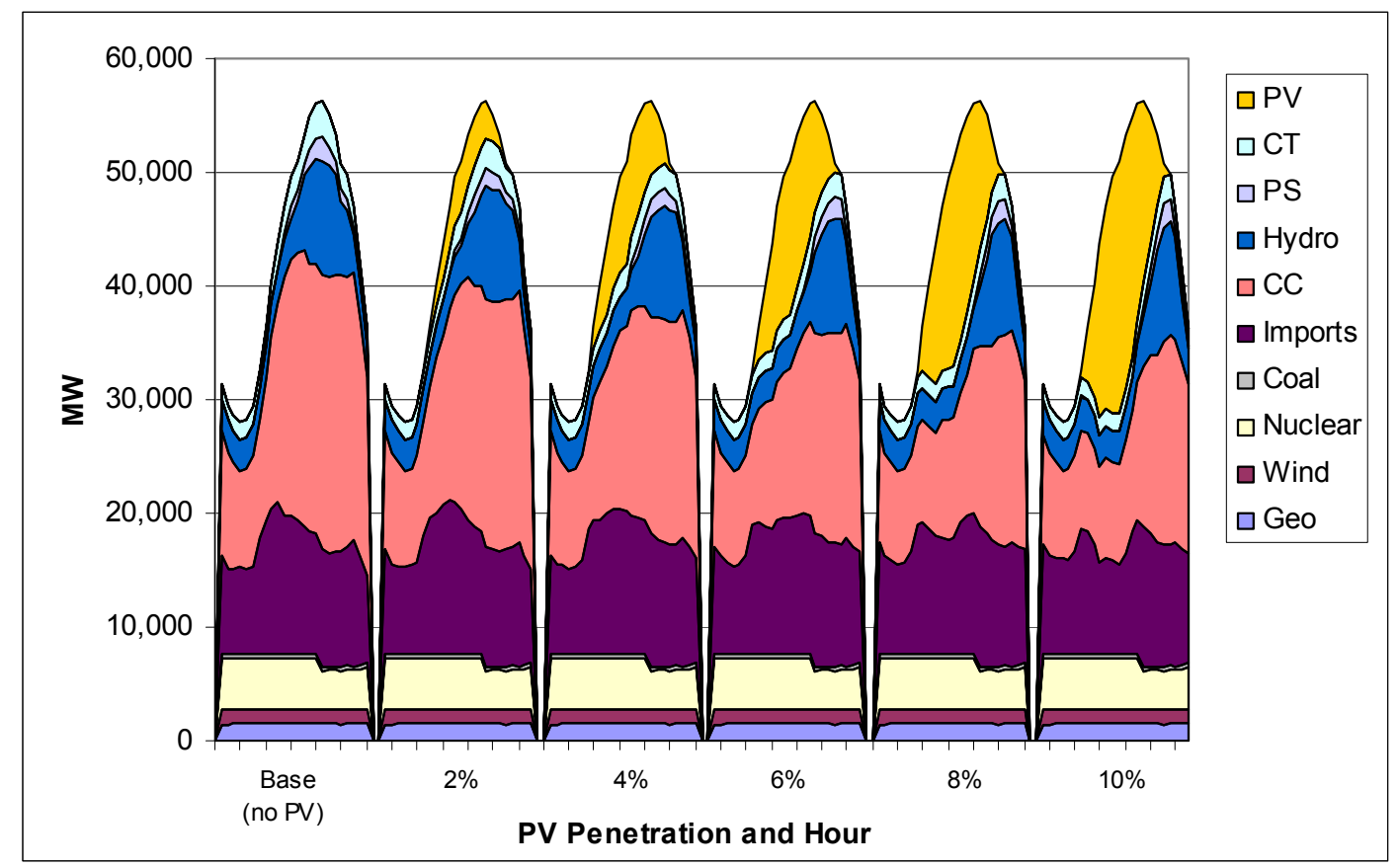

Figure E-1. Simulated Dispatch in California for a Summer Day in 2007 with Various PV Energy Penetration Scenarios

Over the entire WECC region, PV displaces natural gas at low penetration, and begins to displace coal at higher penetration. Figure E-2 illustrates the average avoided fuel for each $\mathrm{kWh}$ of PV generation in the assumed scenario.

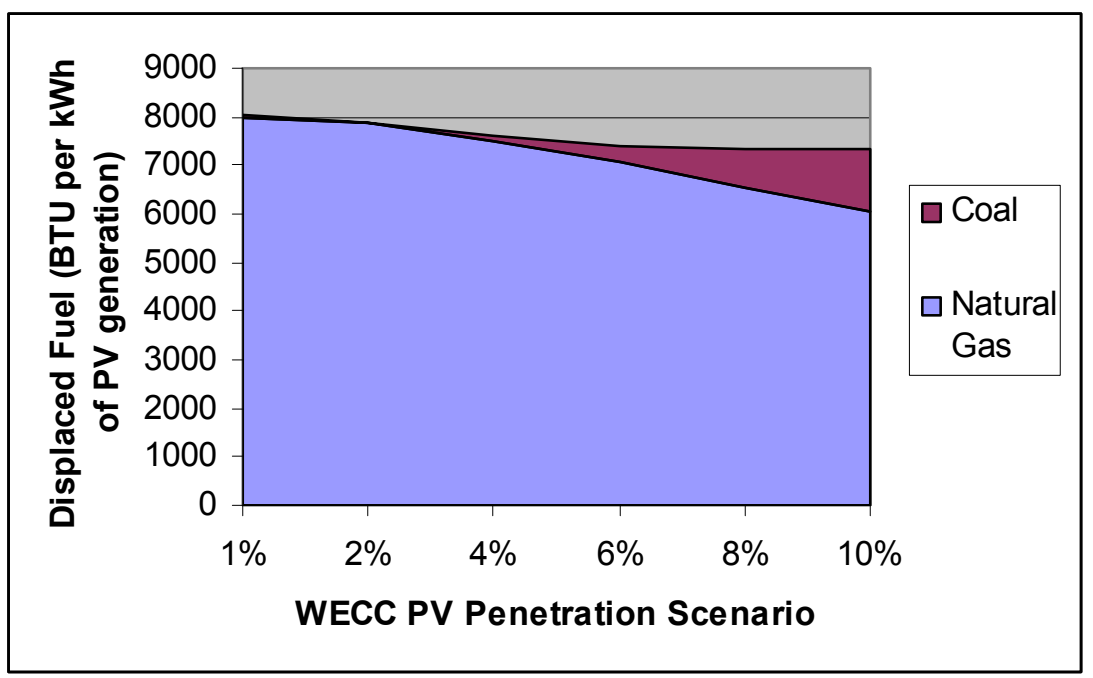

Figure E-2. Average Fuel Displacement Rate from PV Deployed in WECC

The avoided emissions rate from PV depends on the fuel mix, and the changing generator efficiency as a function of load. Figure E-3 illustrates the average and marginal avoided carbon dioxide $\left(\mathrm{CO}_{2}\right)$ emissions rate for the assumed deployment scenario. (The average rate represents the emissions displacement rate for ALL PV generation at a specific 
penetration, while marginal rate represents the emissions displacement rate for the incremental unit of additional PV at a specific penetration level).

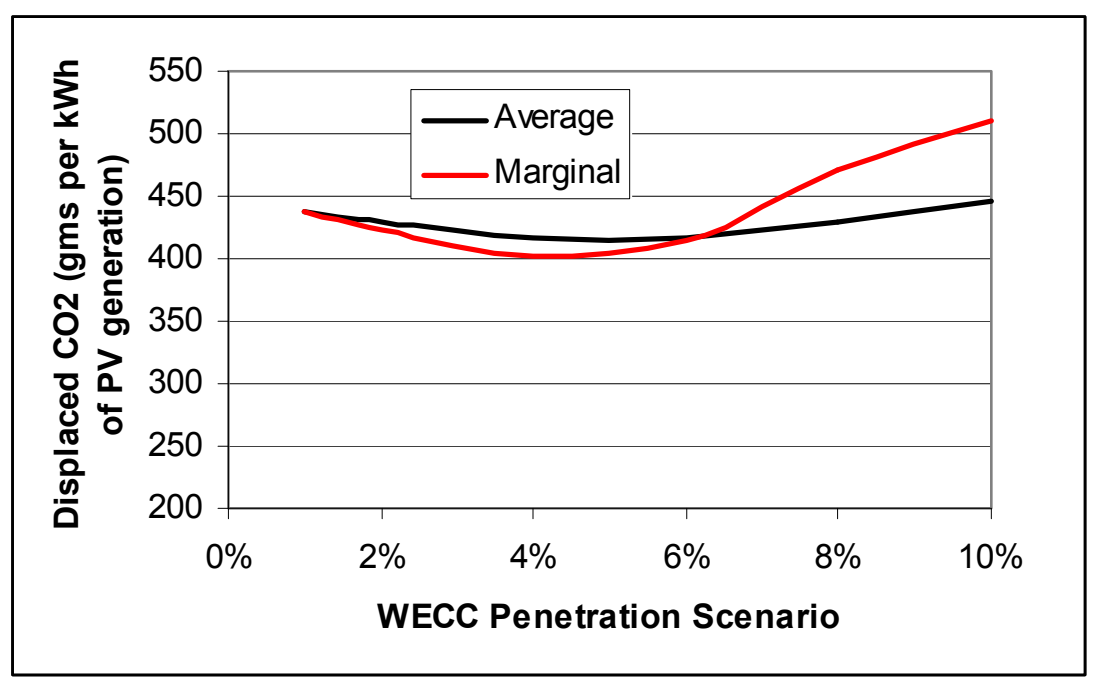

Figure E-3. Average and Marginal $\mathrm{CO}_{2}$ Emissions Displacement from PV Deployed in WECC

In addition to providing estimates of avoided fuels and emissions, this report also considers other analysis needed to evaluate grid-level impacts and benefits of distributed $\mathrm{PV}$. Among these needs are evaluation of the integration costs of PV considering the effects of solar resource forecasting, the ability of generators to follow variations in PV output, decreased T\&D losses, and capacity benefits. 


\section{Table of Contents}

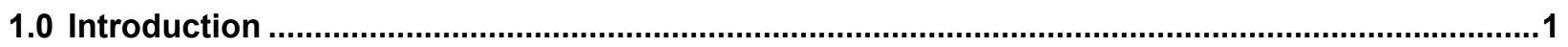

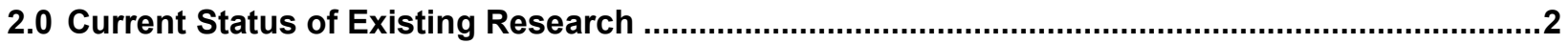

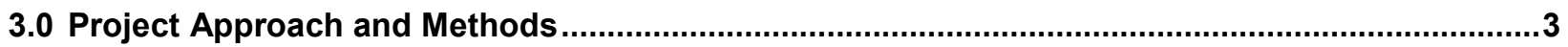

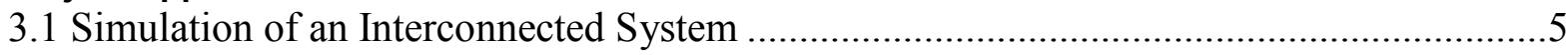

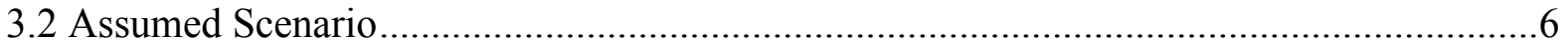

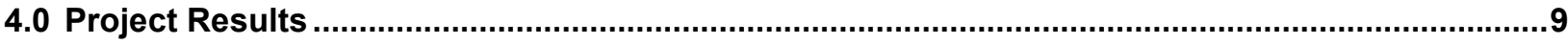

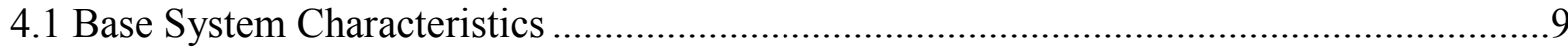

4.2 Load Shape Impacts ............................................................................................ 12

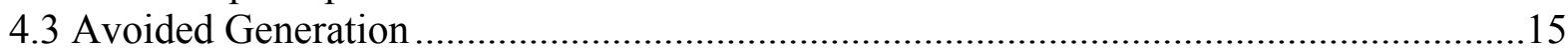

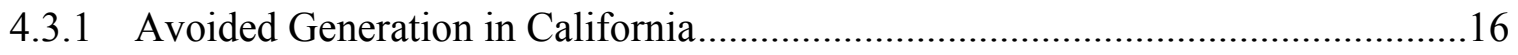

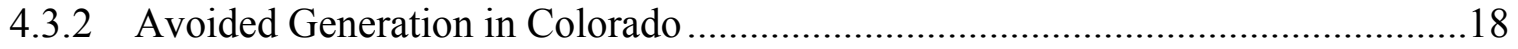

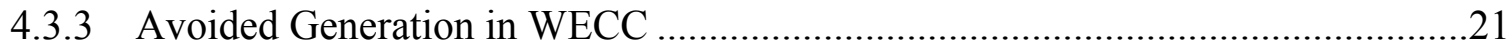

4.4 Avoided Fuel Use ........................................................................................24

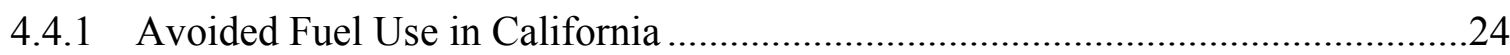

4.4.2 Avoided Fuel Use in Colorado ...................................................................26

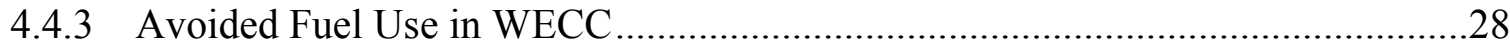

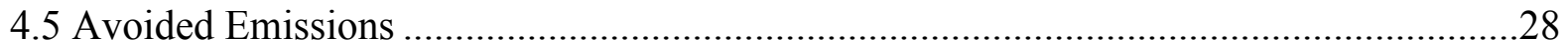

4.5.1 Avoided Emissions in California .................................................................29

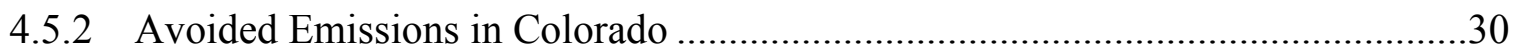

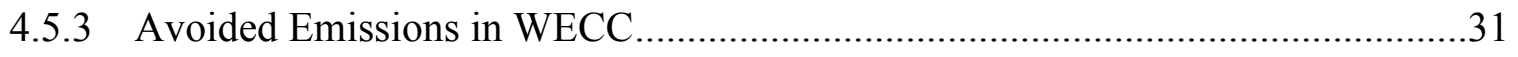

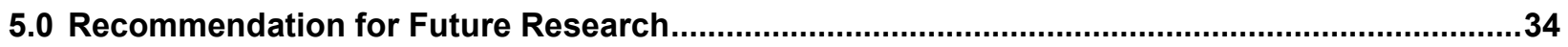

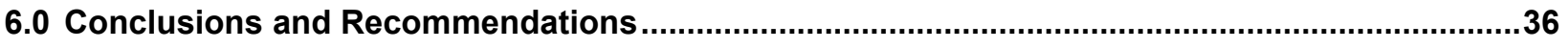

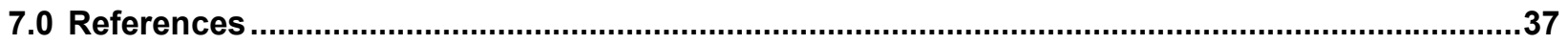




\section{List of Figures}

Figure 1. Representative System Dispatch for a Summer Week ................................... 3

Figure 2. WECC System Topology Used by PROSYM ............................................. 6

Figure 3. Historical Generation Mix and Simulated Generation Mix in WECC ............ 9

Figure 4. Historical Generation Mix and Simulated Generation Mix in California....... 10

Figure 5. Historical Dispatch for CAL-ISO ............................................................. 11

Figure 6. Simulated Dispatch for the State of California ............................................ 12

Figure 7. Load Shapes in Colorado with Various WECC PV Penetration Scenarios.... 13

Figure 8. Load Shapes in California with Various WECC PV Penetration Scenarios .. 13

Figure 9. Load Shapes in WECC with Various PV Penetration Scenarios.................... 14

Figure 10. Load Shapes in WECC with Various PV Penetration Scenarios.................... 15

Figure 11. Simulated Dispatch in California for a Summer Day in 2007 with Various

PV Penetration Scenarios.................................................................... 16

Figure 12. Simulated Dispatch in California for a Winter Day in 2007 with Various

PV Penetration Scenarios..................................................................... 17

Figure 13. Mix of Displaced Generation from PV Deployed in California ..................... 17

Figure 14. Mix of Incremental Displaced Generation from PV Deployed in California. 18

Figure 15. Simulated Dispatch in Colorado for a Spring Day in 2007 with Various PV

Penetration Scenarios

Figure 16. Simulated Dispatch in Colorado for a Summer Day in 2007 with Various PV Penetration Scenarios............................................................................ 20

Figure 17. Mix of Total Displaced Generation from PV Deployed in Colorado ............. 20

Figure 18. Mix of Incremental Displaced Generation from PV Deployed in Colorado .. 21

Figure 19. Simulated Dispatch in WECC for a Winter Day in 2007 with Various PV Penetration Scenarios.................................................................................... 21

Figure 20. Simulated Dispatch in WECC for a Spring Day in 2007 with Various PV Penetration Scenarios........................................................................... 22

Figure 21. Simulated Dispatch in WECC for a Summer Day in 2007 with Various PV Penetration Scenarios.................................................................................. 22

Figure 22. Mix of Total Displaced Generation from PV Deployed in WECC .............. 23

Figure 23. Mix of Incremental Displaced Generation from PV Deployed in WECC...... 23

Figure 24. Average Natural Gas Fuel Displacement from PV Deployed in California and Offsetting California Generation........................................................ 24

Figure 25. Incremental Natural Gas Fuel Displacement from PV Deployed in California and Offsetting California Generation 25

Figure 26. Average Heat Rates of California Natural Gas Generators Resulting from PV Load Following................................................................................ 25

Figure 27. Average Fuel Displacement Rates from PV Deployed in Colorado and Offsetting Colorado Generation.

Figure 28. Total Average Fuel Displacement from PV Deployed in Colorado and Offsetting Colorado Generation.

Figure 29. Incremental Fuel Displacement from PV Deployed in Colorado and Offsetting Colorado Generation.

Figure 30. Total Average Fuel Displacement from PV Deployed in WECC 28 
Figure 31. Incremental Fuel Displacement from PV Deployed in WECC

Figure 32. Average and Marginal $\mathrm{CO}_{2}$ Emissions Displacement from PV Deployed in California and Offsetting California Generation

Figure 33. Average and Marginal $\mathrm{NO}_{\mathrm{X}}$ Emissions Displacement from PV Deployed in California and Offsetting California Generation ....................................... 30

Figure 34. Total Average $\mathrm{CO}_{2}$ Emissions Displacement from PV Deployed in Colorado and Offsetting Colorado Generation 30

Figure 35. Incremental $\mathrm{CO}_{2}$ Emissions Displacement from PV Deployed in Colorado and Offsetting Colorado Generation.

Figure 36. Average and Marginal $\mathrm{NO}_{\mathrm{X}}$ and $\mathrm{SO}_{2}$ Emissions Displacement from PV Deployed in Colorado and Offsetting Colorado Generation

Figure 37. Average and Marginal $\mathrm{CO}_{2}$ Emissions Displacement from PV Deployed in WECC.

Figure 38. Seasonal Incremental $\mathrm{CO}_{2}$ Emissions Displacement from PV Deployed in WECC

Figure 39. Average and Marginal $\mathrm{NO}_{\mathrm{X}}$ and $\mathrm{SO}_{2}$ Emissions Displacement from $\mathrm{PV}$ Deployed in WECC 


\section{List of Tables}

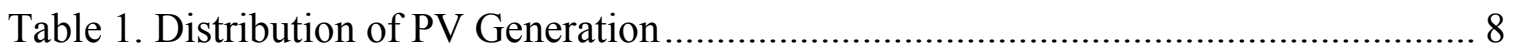




\subsection{Introduction}

Solar photovoltaic (PV) technology is being deployed in part to reduce dependence on fossil fuels for electricity use and associated emissions of greenhouse gases and criteria pollutants such as nitrous oxides $\left(\mathrm{NO}_{\mathrm{x}}\right)$ and sulfur dioxide $\left(\mathrm{SO}_{2}\right)$. Given the time-varying output of $\mathrm{PV}$, and the diverse set of electric generators in the power plant fleet, there is considerable uncertainty as to the actual benefits of PV in various regions. Simple gridaverage emissions and fuel use provide unsatisfactory estimates of actual benefits given the peak-coincidence aspects of PV, along with the potentially significant difference between the average grid and the generators "on the margin." The power plants that can be backed off in response to the mid-day generation of PV electricity may be quite different from those providing constant baseload power.

This report uses a production cost modeling approach to evaluate the large scale interaction of solar electricity technologies with the existing and possible future grid, with a focus on displaced generation capacity, fuel saved, and emissions avoided by deploying varying levels of solar electric generation. This study established a PV penetration scenario in several regions in the United States and simulates the response of the power plant fleet. While focusing on avoided fuels and emissions that result from PV deployment, this analysis also identifies areas of future research to increase understanding of benefits and impacts of large-scale PV deployment. 


\subsection{Current Status of Existing Research}

There are a number of approaches used to estimate the displaced fuels and emissions associated with the deployment of renewable energy technologies. The most basic approach is to use regional "grid averages." Average analysis provides a very simple method to estimate system benefits of PV [1]. Given the time-varying nature of both PV output and power plant operation, "marginal" analysis provides a greater degree of accuracy when determining emissions or fuel displacement.

There are two general methods to marginal grid analysis that can be generally classified as "accounting" and "modeling."[2] Accounting methods attempt to collect historical generation information to estimate those units that are likely to reduce generation in response to the output from a renewable source such as PV. There are a number of advantages to this approach, one of which is a fairly realistic reflection of the current grid, and current grid operations strategies. Data sets used include estimates from individual utilities, various historical plant-level data sets, and more recently, the EPA continuous emissions monitoring system (CEMS) databases. Accounting methods have been previously used to estimate the impacts of limited deployment of PV [3-6].

Among the most significant limitations of accounting methods is the limited ability to "redispatch" the system based on changes in the generation mix due to the introduction of new generation technologies, including more than a relatively small amount of renewable energy generation. The use of simulation models allows for system re dispatch, and also allows for greater examination of the use of transmission. Models also allow for the dispatch of hydro resources, which may be important when simulating relatively large penetration of intermittent renewables. 


\subsection{Project Approach and Methods}

The approach of this study is to simulate the operation of electric power systems using a utility power plant dispatch model. Power plant dispatch is based on the actual operating (variable) cost of generation, including both fuel and operation and maintenance. Plants are dispatched from lowest to highest cost, based on the load, plant availability, and a variety of system constraints, such as power plant start-up times, ramp rates, environmental restrictions, transmission congestion, etc. Figure 1 illustrates an example dispatch scenario. The power plants dispatched first are those with the lowest variable costs, including nuclear, geothermal, and wind units. Some of these generation types, such as wind, have essentially zero variable cost, and are not controllable. Others, like nuclear, have some small fuel cost, but are difficult to ramp. Coal units typically have the next lowest cost, followed by combined-cycle (CC) and single-cycle gas turbines (CT).

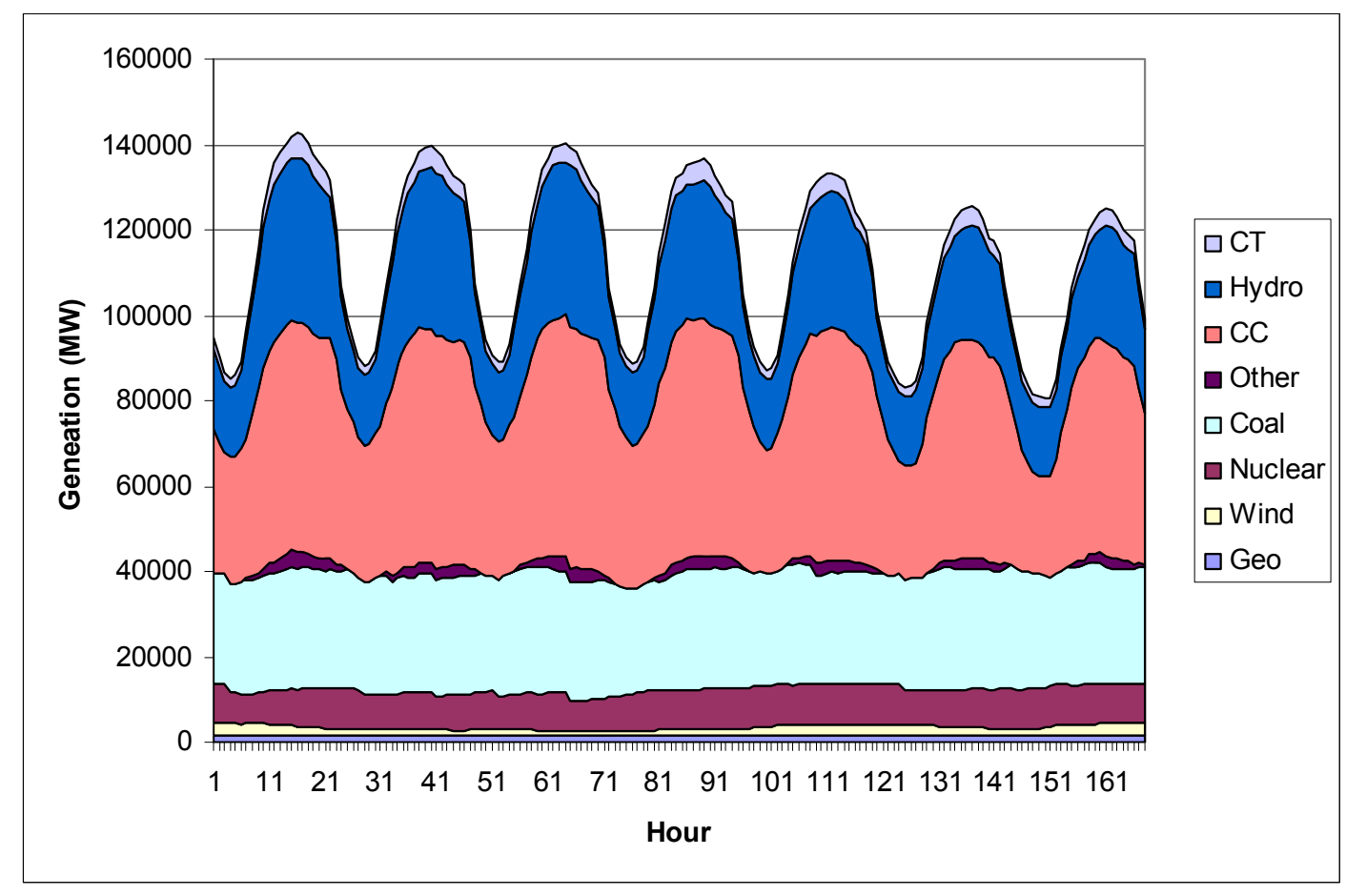

Figure 1. Representative System Dispatch for a Summer Week

As can be observed, hydro dispatch is performed in a somewhat different manner from conventional thermal plants. It has essentially zero fuel cost, but also has limited energy availability. Hydro units also have the ability to ramp very quickly in response to variation in load. ${ }^{1}$ Hydro is therefore typically dispatched as a load following and peaking plant, while operating under various environmental, recreation, and regulatory constraints of minimum and maximum water flows.

\footnotetext{
${ }^{1}$ Assumes hydro with dam storage, not "run-of-river" type plants.
} 
During real-time operations, increased load results in an increase in generation from the least cost unit available, while any reduction in the system load will result in the highest cost unit being "backed off." The marginal or incremental unit(s) vary from hour to hour. As can be seen in Figure 1, any decrease in mid-day electric demand will affect primarily the CC units. Only after a substantial load reduction would there be any effect on coal units.

Utility system operators use a number of tools that estimate the most optimal dispatch of individual generators. These tools are referred to by several names, including "production cost," "unit commitment and dispatch," or "chronological dispatch" models. A high quality production cost model takes into account not only the variable cost of operating each plant, but also the large number of generator and system constraints to solve the optimal dispatch of all power plants in a utility fleet or an entire region. These constraints include several that may be very important when evaluating the impacts of PV.

Each power plant has operational limits, including the ability to ramp, minimum up and down times, and minimum loading. At high penetration of PV, the ability of power plants to reduce output may limit the amount of PV that can be accepted into the grid [7]. In addition to operational limits, each power plant has an efficiency or heat rate (fuel used per unit of generation) that varies as a function of load. As PV penetration increases, power plants may need to cycle more, resulting in lower average efficiency. This cycling could reduce the average fuel use and emissions offset as a function of PV penetration. (It will also increase the average cost of generation from thermal units, along with maintenance requirements. While the integration cost impacts of PV are an important consideration, they were not analyzed in this study.)

It should also be noted that while operational limits at the generator level are considered, there may be limits of PV deployment within the distribution system. These limitations are discussed in detail in several of the other Renewable Systems Interconnection studies.

For this study, we evaluated the optimal dispatch of power plants in several regions of the United States with and without PV. This evaluation consisted of performing a "base" run in each region without PV ( $0 \%$ PV penetration), then adding PV using simulated output from a distributed PV network.

The tool used for this study is PROSYM, offered by Global Energy Decisions. The tool comes with a database of the U.S. generation fleet, including heat rate curves and such constraints as minimum loading levels, along with a "reduced form" approximation of the transmission system. Accounting for transmission is one of the significant challenges in modeling electric power systems. The interconnected nature of the U.S. grid, and the power exchanges that occur over large regions must be considered when attempting to optimally dispatch the system as a whole. 


\subsection{Simulation of an Interconnected System}

The electric power system in the United States consists of three large grids: the Eastern Interconnect, Western Interconnect (also known as the Western Electricity Coordinating Council or WECC), and the ERCOT (Texas) grid. All generators in each interconnect are synchronized and power may flow from any point to another within each grid, assuming transmission availability.

The use of transmission within each grid allows for a more reliable and cost-optimal system as a whole. Utilities typically contract for power and energy from other regions through a variety of open market and bilateral contracts, within the constraints of generation and transmission availability. This interconnectedness provides challenges when simulating the grid in any particular region. While utilities in certain areas may have sufficient generation to meet their load, it may be far more efficient for those utilities to purchase energy from a utility in a different region than run their own generation.

This study uses a "centralized dispatch" approach to system operation. PROSYM evaluates the system as a whole, dispatching all generators to optimize for least cost performance. This assumption is based in part on the existing levels of communication and cooperation that exist today, even though WECC is not centrally dispatched. Furthermore, it will be some time before PV achieves the high level of penetration evaluated in this study, and the electric power system will change physically and operationally. While we do not necessarily assume that WECC as a whole will become part of a centralized dispatched system or a single market, it is likely that continuous improvements in communication of price signals, transmission availability, etc, allow for our centralized dispatch model to be a reasonable approximation of the future electric power system as a whole.

Figure 2 provides the topology for this study. Within PROSYM, the Western Interconnect (WECC) is divided into a number of transmission areas, each comprising a load and a number of generators [8]. Within each transmission area, load flows are essentially unconstrained. Transmission between regions is modeled with a reduced form approximation based on a rated link between each transmission area. Power may flow between transmission areas, limited by path ratings, and taking into account line losses. 


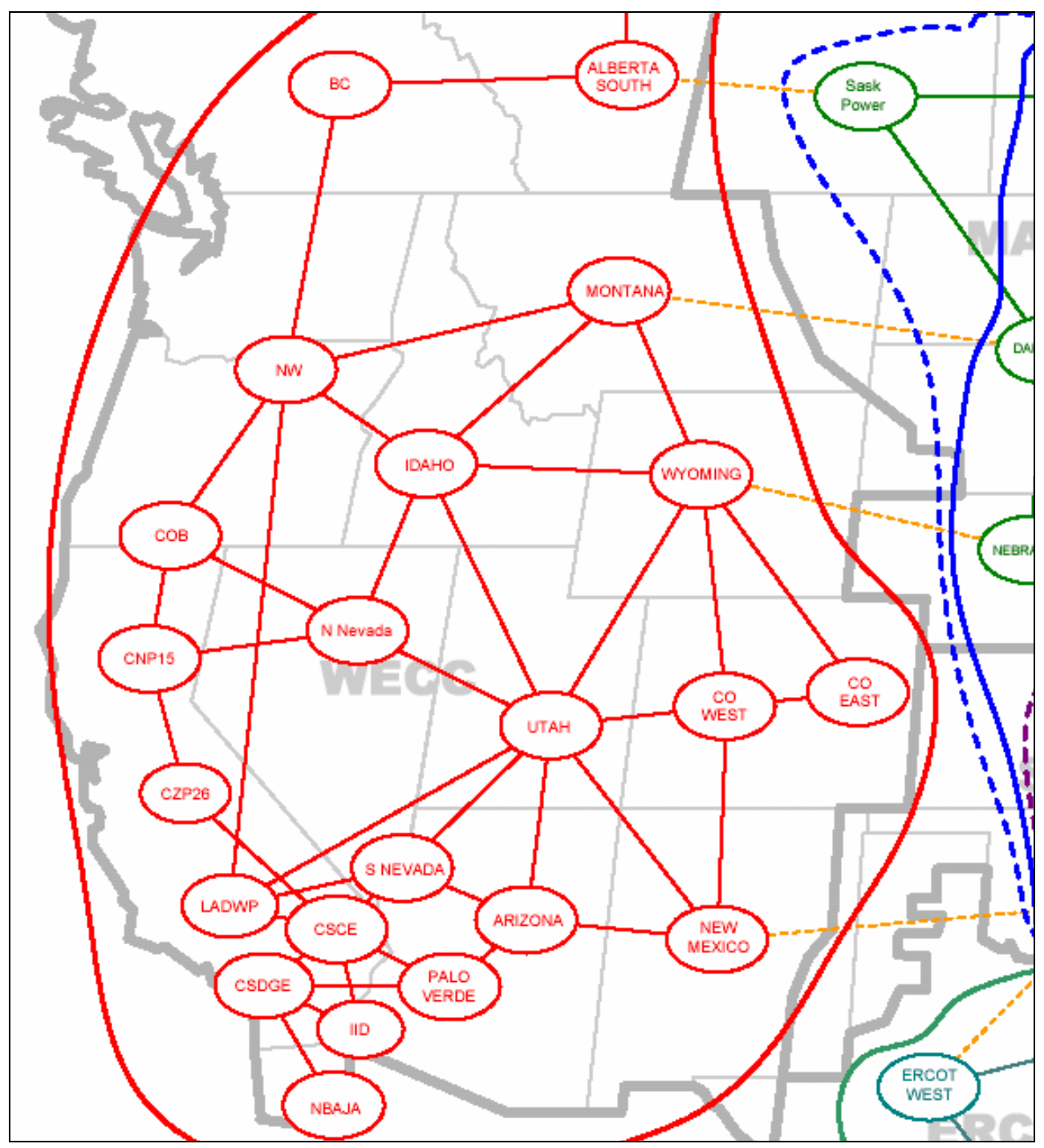

Figure 2. WECC System Topology Used by PROSYM

For this study, we examined the impacts of PV on three aggregated regions - the state of California, consisting of seven transmission areas, the state of Colorado, consisting of two transmission areas, and the entire WECC region.

\subsection{Assumed Scenario}

Without generating a regional PV penetration scenario, it is not possible to capture the real power exchanges that will occur in an interconnected system. Therefore, it is important to create a scenario of PV deployment that considers interaction of local PV generation within the area of specific interest with the surrounding system. We generated a single overall scenario with PV deployment throughout the WECC region, while focusing on generator operation within California and Colorado. The scenario actually consists of a series of PV penetrations in which $1 \%$ to $10 \%$ of the entire western interconnect's annual electrical energy is derived from PV. 
We began by obtaining hourly solar radiation data from the updated National Solar Radiation Database (NSRDB) [10], and simulating the performance of PV systems deployed at a variety of locations and orientations. A total of 75 sites within WECC were simulated, with each site having 14 possible configurations representing homes and buildings with various roof pitches and orientations, and also the use of utility tracking arrays. Since there is considerable correlation between system load, weather, and solar insolation, the solar data must match the load year. For this study, we chose 2003 as our base year for both insolation and load.

After the hourly solar output was simulated at each of the site and orientation combinations, a composite PV output was generated for each of the transmission areas modeled within PROSYM. This composite output was generated by weighing the contribution from each location based on its population. (We assumed that PV within a transmission area would be deployed roughly in proportion to local population, and we used Census data to match population with the distribution of PV.)

Once a composite hourly PV output was generated for each transmission area, an overall regional penetration scenario was developed. The base assumption is that PV will be built in states with the highest level of driving factors, including high electricity prices, incentives, political support, progressive utilities and rate structures, and good insolation.

Table 1 provides a list of the transmission areas that were assigned PV generation. 
Table 1. Distribution of PV Generation

\begin{tabular}{|l|c|c|c|c|}
\hline $\begin{array}{l}\text { Transmission } \\
\text { Area }\end{array}$ & $\begin{array}{c}\text { Fraction of } \\
\text { Total WECC } \\
\text { Load (2007) }\end{array}$ & $\begin{array}{c}\text { Fraction of } \\
\text { WECC PV } \\
\text { Capacity }\end{array}$ & $\begin{array}{c}\text { Fraction of } \\
\text { WECC PV } \\
\text { Energy }\end{array}$ & $\begin{array}{c}\text { Fraction of } \\
\text { Region's Load } \\
\text { Met by PV in } \\
\text { the 10\% Energy } \\
\text { Scenario }\end{array}$ \\
\hline Arizona & $8.4 \%$ & $10.0 \%$ & $11.3 \%$ & $14.7 \%$ \\
\hline $\begin{array}{l}\text { Northern California } \\
\text { (NP26 + CZP26) }\end{array}$ & $14.3 \%$ & $22.2 \%$ & $21.7 \%$ & $14.2 \%$ \\
\hline $\begin{array}{l}\text { San Diego Gas \& } \\
\text { Electric }\end{array}$ & $2.5 \%$ & $4.0 \%$ & $4.2 \%$ & $17.1 \%$ \\
\hline Southern Cal. Edison & $13.2 \%$ & $21.2 \%$ & $22.2 \%$ & $17.0 \%$ \\
\hline $\begin{array}{l}\text { Los Angeles Dept. of } \\
\text { Water \& Power }\end{array}$ & $3.5 \%$ & $5.6 \%$ & $5.9 \%$ & $14.1 \%$ \\
\hline $\begin{array}{l}\text { Imperial Irrigation } \\
\text { District }\end{array}$ & $0.4 \%$ & $0.6 \%$ & $0.7 \%$ & $18.0 \%$ \\
\hline Northern Nevada & $1.5 \%$ & $1.4 \%$ & $1.5 \%$ & $10.5 \%$ \\
\hline Southern Nevada & $3.4 \%$ & $3.1 \%$ & $3.5 \%$ & $11.0 \%$ \\
\hline Idaho Southwest & $1.7 \%$ & $1.2 \%$ & $1.2 \%$ & $6.2 \%$ \\
\hline New Mexico & $2.7 \%$ & $3.2 \%$ & $3.7 \%$ & $15.0 \%$ \\
\hline Utah & $3.7 \%$ & $3.9 \%$ & $3.8 \%$ & $9.5 \%$ \\
\hline $\begin{array}{l}\text { Northwest All of WA, } \\
\text { OR, and far W. Mont. }\end{array}$ & $17.7 \%$ & $15.5 \%$ & $11.9 \%$ & $5.0 \%$ \\
\hline Colorado West & $0.7 \%$ & $1.1 \%$ & $1.0 \%$ & $11.1 \%$ \\
\hline Colorado East & $5.5 \%$ & $7.0 \%$ & $7.4 \%$ & $13.8 \%$ \\
\hline Remainder of WECC & $19.7 \%$ & $0 \%$ & $0 \%$ & $0 \%$ \\
\hline
\end{tabular}

The majority of PV is assumed to be constructed in California (well over 50\%). No PV was assigned to several regions, including the two Canadian provinces in WECC and the Northeastern part of WECC, including Wyoming, Eastern Idaho, and Montana.

Based on the geographical weighting of PV locations, the various overall penetration scenarios were created. Penetration scenarios were developed based on a $1 \%, 2 \%, 4 \%, 6 \%$, $8 \%$, and $10 \%$ penetration (by annual energy) of $\mathrm{PV}$ in the entire WECC region. It is important to consider this when evaluating the results of this study, particularly the results of the individual state analysis. In both the Colorado and California studies, the actual penetration of PV on an energy basis is higher than the named scenario. In the $10 \%$ scenario, PV is actually generating energy sufficient to meet $13.5 \%$ of Colorado's load, and $15.6 \%$ of California's load. Since scale factors were applied linearly, these adjustment factors can be applied to each of the named scenarios. (For example, in the $2 \%$ scenario, Colorado PV generation is equal to $2 \% * 1.135$ and California PV generation is equal $2 * 1.156$ etc.)

Model runs were performed for 2007, 2015, and 2020. Future loads are simple linear extractions based on estimated growth rates. It is important to note that the relative penetration of PV remains constant, so the only real change between the yearly simulations are changes in the regional generation mix. The generation mix for future years is built into the PROSYM model, based on a "business as usual" scenario that includes certain state RPS policies, but no aggressive policies towards climate change. It is possible, however, to include such scenarios by altering the generation mix, or including carbon taxes or caps. 


\subsection{Project Results}

To track various performance metrics, all generators in WECC were categorized into several groupings: combined-cycle gas turbines $(\mathrm{CC})$, simple-cycle gas turbines $(\mathrm{CT}$, in which we included gas-fired steam turbines and reciprocating engines to represent peaking plants), coal, nuclear, geothermal, hydro, pumped hydro storage, and wind. A relatively small number of plants not fitting these categories (mostly small thermal plants fired by a variety of fuels, including wood, waste, landfill gas, petroleum coke, etc.) were placed into an "other" category.

Simulation runs were performed for a base case $(0 \% \mathrm{PV})$ and for each of the penetration scenarios. Hourly generation and fuel use was tracked from each power plant category, and emissions of carbon dioxide $\left(\mathrm{CO}_{2}\right)$ were tracked on a monthly basis. While one of the primary uses of production cost models is to track generation-related costs, these were not evaluated in this study.

\subsection{Base System Characteristics}

Base case runs (no additional PV) were performed with PROSYM to estimate the fuel mix for the current and future year scenarios. The results of the runs were also compared to historical data in an attempt to validate model assumptions.

Figure 3 indicates the WECC fuel mix for the study years, compared to actual data. The projected fuel mix changes slightly, with an increase in the fractional generation from gas and wind, and a decrease in fractional generation from coal.

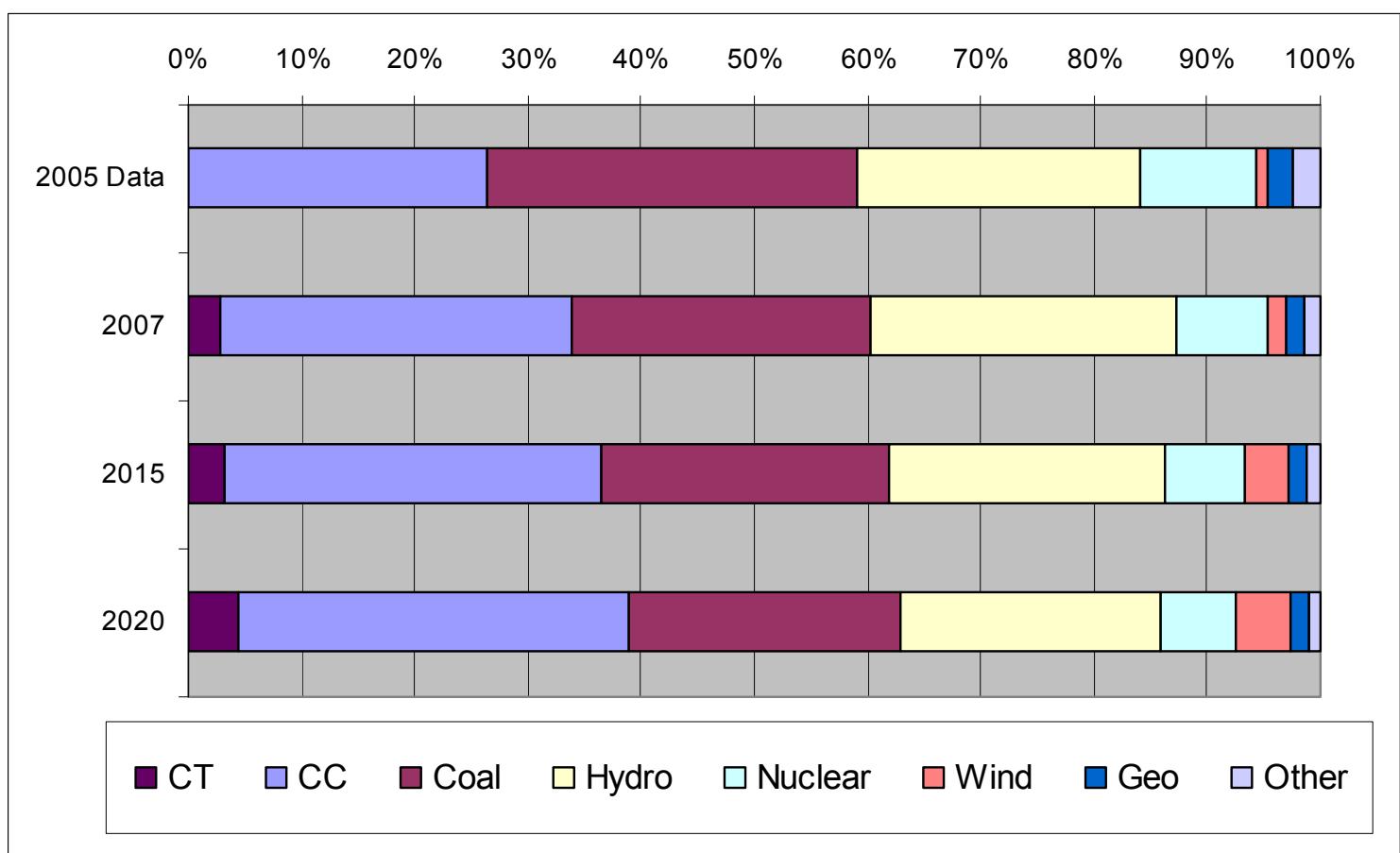

Figure 3. Historical Generation Mix and Simulated Generation Mix in WECC 
The most significant difference between the 2005 data and 2007 estimates is the fractional use of gas generation. (It should be noted that all gas-fired generation from the 2005 data, including combined- and simple-cycle gas turbines and gas steam units were included in the CC category). There are several possible explanations for this discrepancy. First, the amount of gas-fired generation has increased since 2005, accommodating virtually all the baseload growth in the demand. In addition, there are certain accounting differences in the "other" category for both the 2005 data and the 2007 model runs. In the 2007 simulations, the "CT" category actually includes all peaking plants, including those liquid-fueled steam turbines, and internal combustion engines. Some of these units are actually included in the "other" category in the 2005 data.

There are several other caveats regarding the comparison between the 2005 data and the future projections. The PROSYM simulations include British Columbia, Alberta, and Baja California, while the 2005 data includes only U.S. generation. These non-U.S. areas account for about $17 \%$ of the entire WECC load and may account for some of the differences. Finally, there is significant variation in hydro resource from year to year. Further data analysis is necessary to estimate the actual differences between historical data and model estimates, accounting for the differences in power plant accounting, nonU.S. generation, and hydro variation. ${ }^{2}$

Also compared was generation data for two states: California and Colorado. Figure 4 compares actual 2005 data with 2007 simulations for the state of California. As previously, important caveats include variation in hydro availability, and accounting differences for a number of thermal generators using fuels other than coal and natural gas.

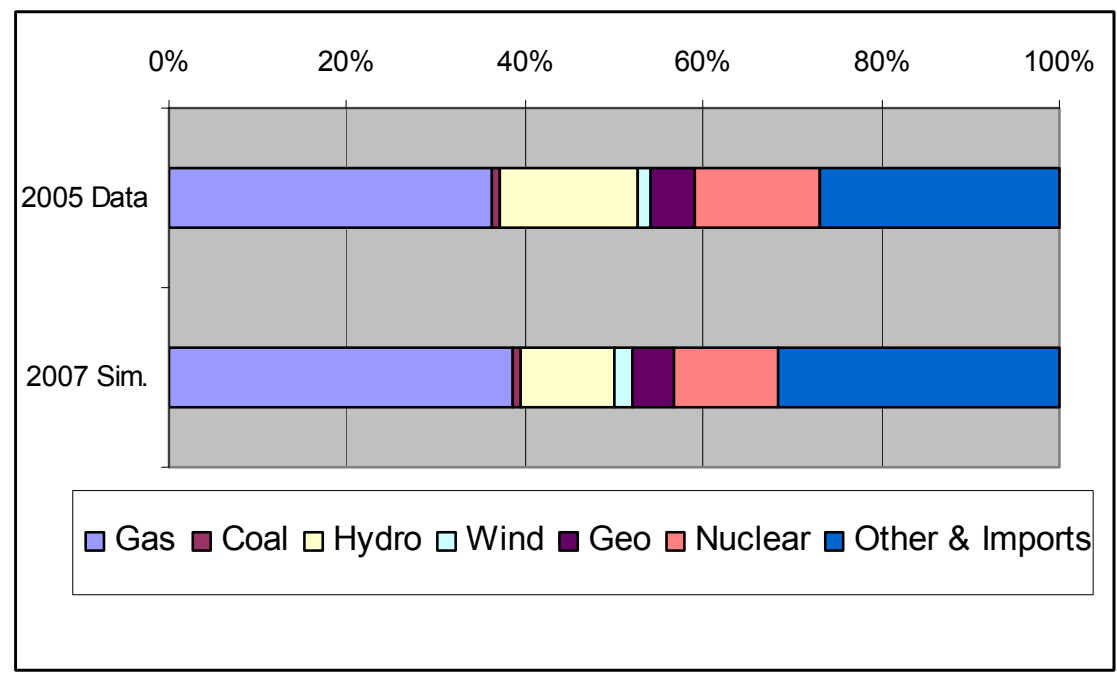

Figure 4. Historical Generation Mix and Simulated Generation Mix in California

\footnotetext{
${ }^{2}$ A forthcoming version of this report will attempt to further reconcile the differences in historical data with simulations by comparing plant level performance and identifying any real differences. Also, the power plant data within PROSYM will be recategorized to isolate non-U.S. generators.
} 
Figure 5 and Figure 6 compare an estimated actual plant dispatch in the California ISO from a summer day in 2006 [9] to a simulated dispatch in California in 2007. The simulated California dispatch includes the entire state, while the California ISO does not include several parts of northern and eastern California, and the Los Angeles Department of Water \& Power, together accounting for about $12 \%$ of the state's load. Actual plant dispatch is difficult to compare because of how various plants are categorized. In the actual dispatch, both "thermal" stations and qualifying facilities include a large number of plant types, including CCs, geothermal, and industrial cogeneration plants (some of which may utilize CTs).

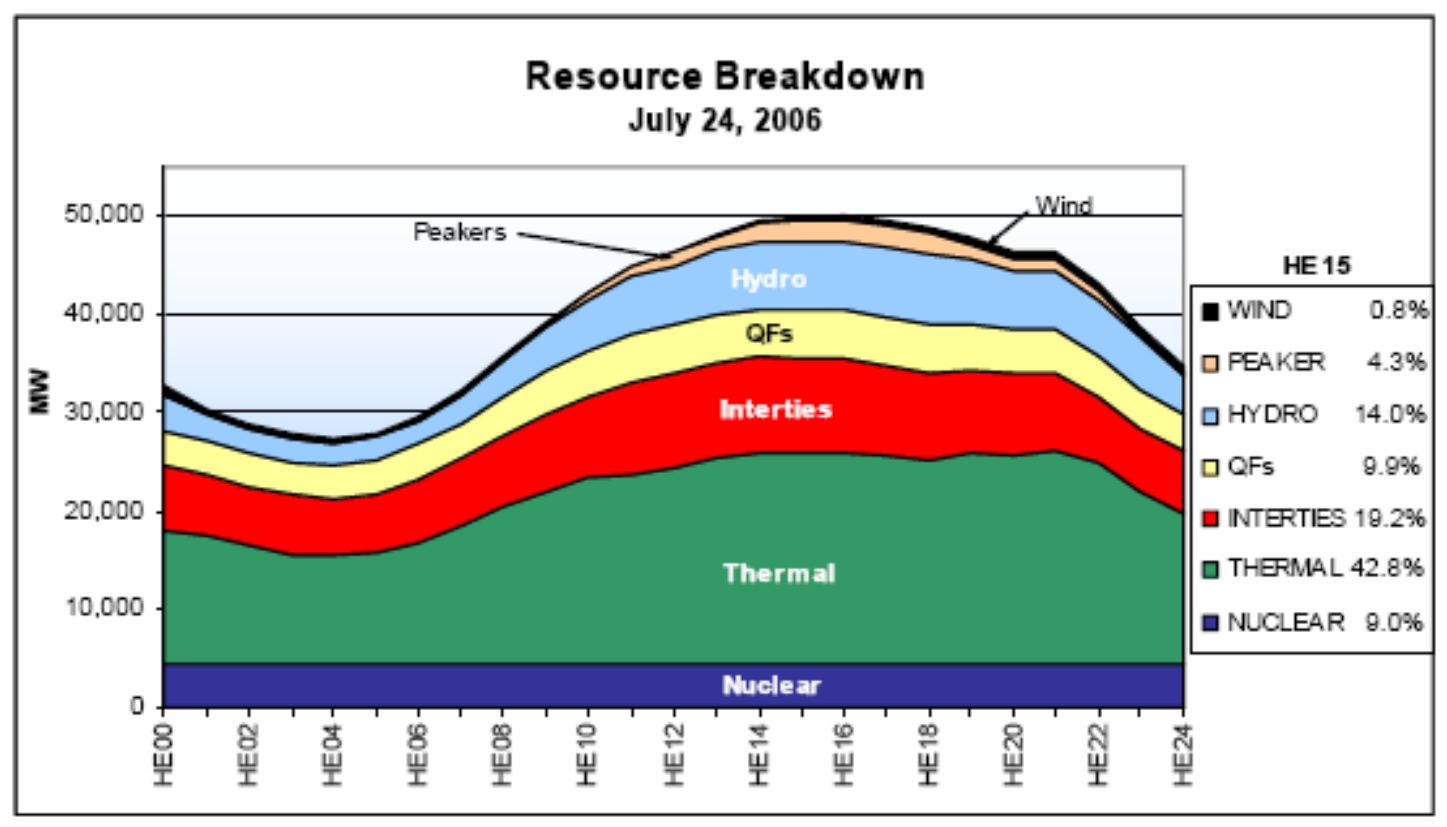

Figure 5. Historical Dispatch for CAL-ISO 


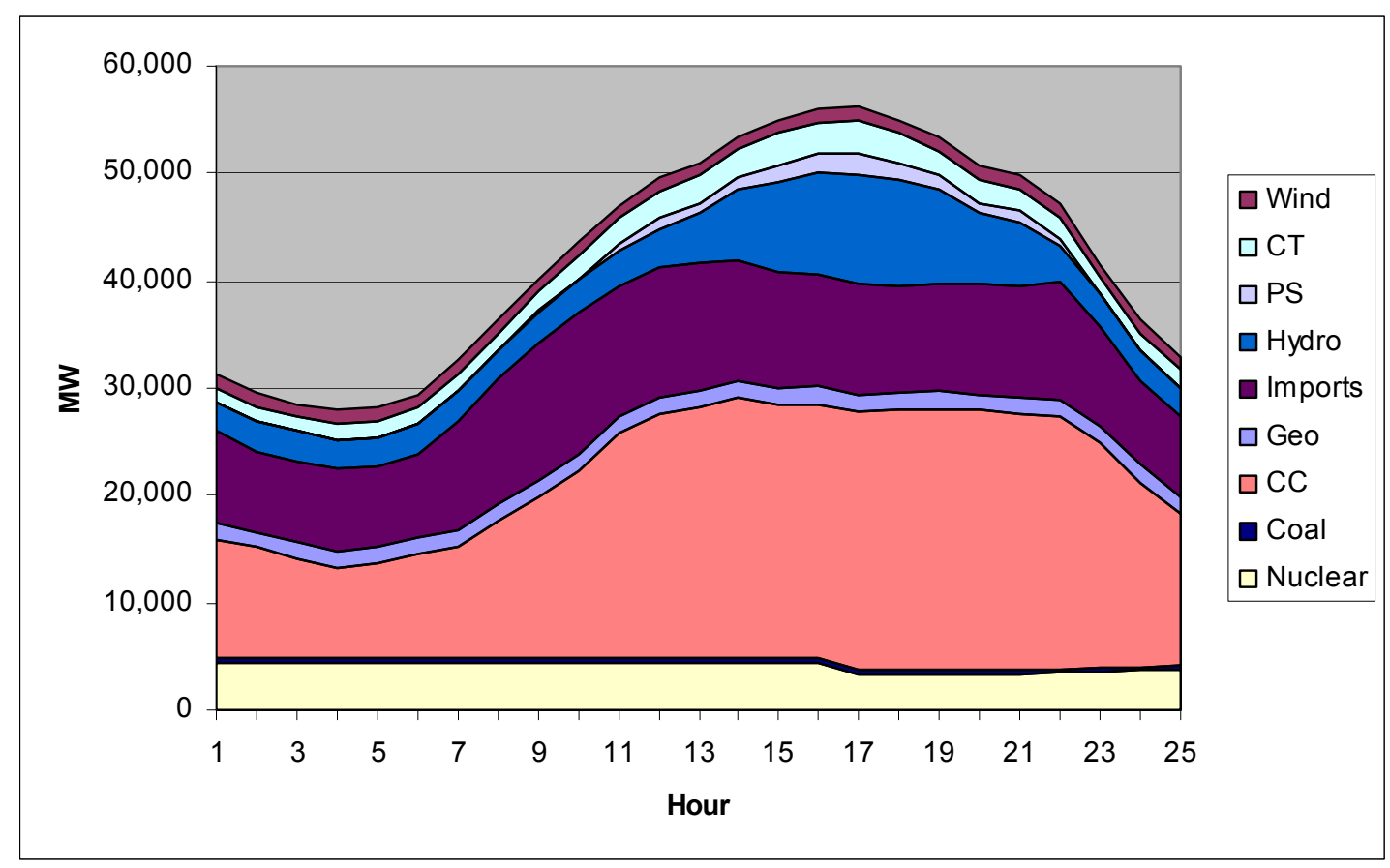

Figure 6. Simulated Dispatch for the State of California

It is important to note that it is inappropriate to compare the actual plant dispatch to the simulated plant dispatch in any given hour, or over very short time periods. Variations in plant outages, wind availability, and various operational considerations make such a direct comparison of short-term data of limited value. Production cost model simulations may include both scheduled outages and random forced outages, or forced output reductions, which will not match "real" outages. As a result, this study is not intended to evaluate the impact of PV during a specific hour or day, but is intended to evaluate the longer-term impacts (seasonal to annual) of PV deployment.

\subsection{Load Shape Impacts}

Introduction of customer-sited PV will change the overall load and load shape met by conventional generation. The amount of load reduction and the time and season of load reduction will determine the mix of avoided generation.

Figure 7, Figure 8, and Figure 9 illustrate the type and magnitude of load shape impacts created by the various levels of PV penetration in each region. The $1 \%$ case is omitted for clarity. In each graph, three representative 2-day periods (summer, spring minimum, and summer maximum) are used to illustrate simulated PV impacts for the year 2007. During the winter, variation in electricity demand is driven largely by heating and lighting, with two daily peaks: a morning peak and a larger evening peak driven largely by lighting. Winter PV generation occurs in between these two peaks and will not reduce overall peak demand. Spring loads are fairly flat during the daytime given the minimal need for heating or air-conditioning, with a relatively small evening lighting peak, again unaffected by PV generation. The minimum demand for electricity generally occurs in the overnight hours in the spring season. Summertime peak loads are driven by air 
conditioning demand, which is largely coincident with PV output. As a result, PV can act to reduce peak demand, and will act to offset generation from potentially lower efficiency peaking plants, such as simple-cycle combustion turbines.

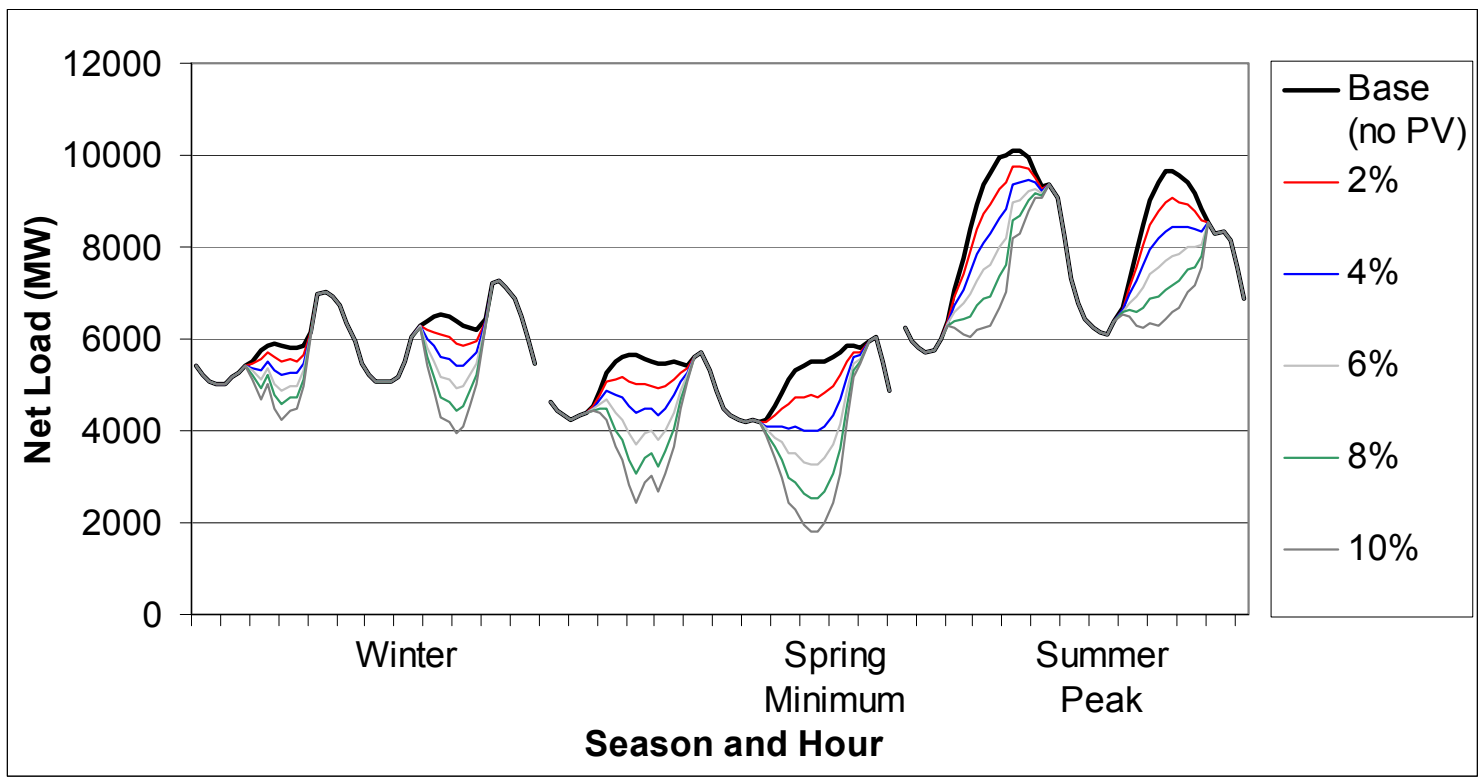

Figure 7. Load Shapes in Colorado with Various WECC PV Penetration Scenarios

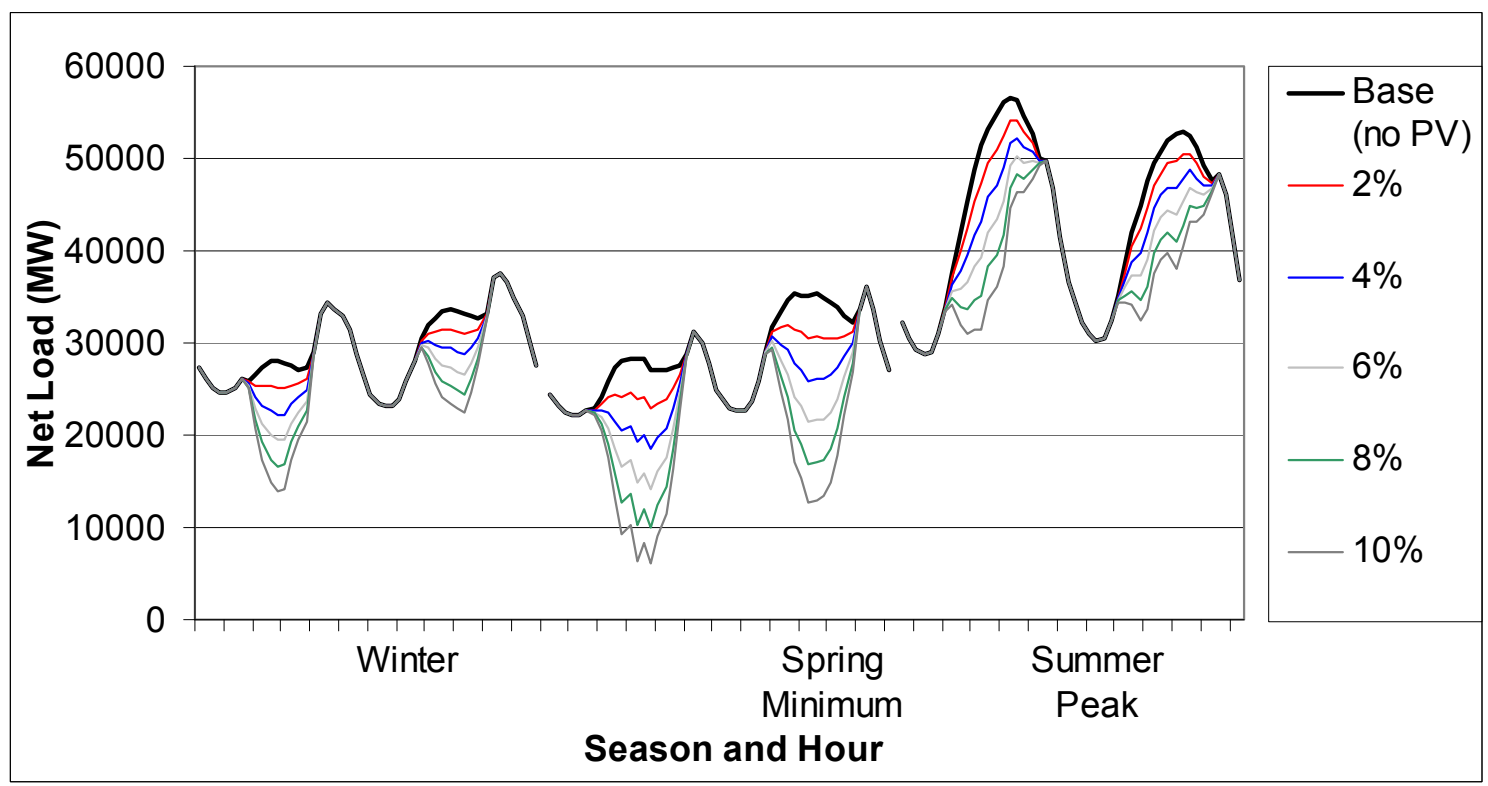

Figure 8. Load Shapes in California with Various WECC PV Penetration Scenarios 


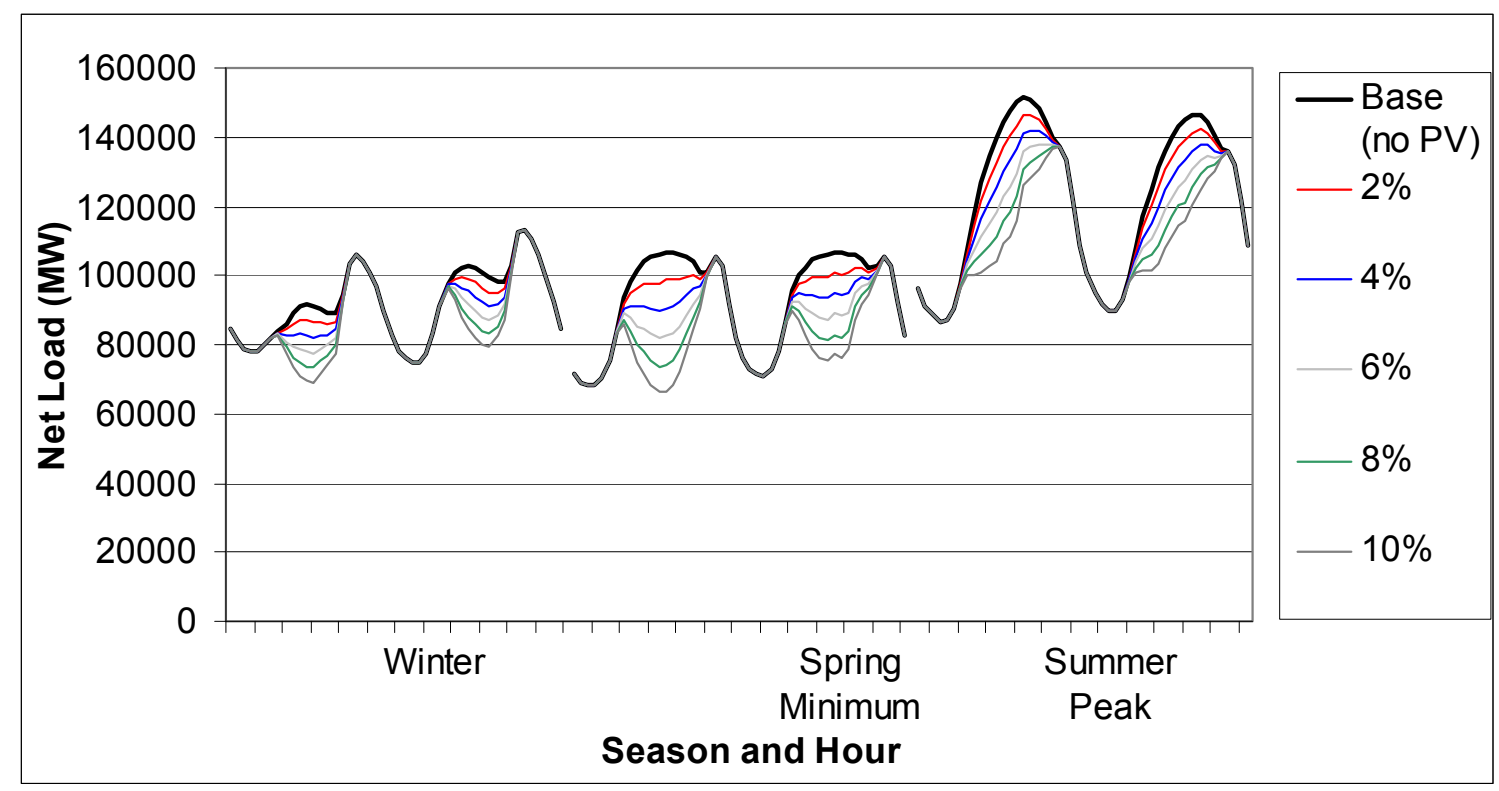

Figure 9. Load Shapes in WECC with Various PV Penetration Scenarios

The overall load shapes in California, Colorado, and WECC as a whole (which includes both California and Colorado) are fairly similar. The net load shape with PV in WECC is considerably smoother than in the individual states. This is largely due to the aggregation of the 75 PV locations, while the net loads in individual states use fewer PV sites. In reality, the composite PV profile in a state will potentially be smoother due to the large number of distributed PV sites. While probably not a major influence of the outcome of this study, the more irregular PV profile might increase the ramping requirement of the system, and future studies should probably include many more sites within each transmission area. ${ }^{3}$

Overall general impacts on loads can be observed through the use of a Load Duration Curve (LDC). Figure 10 illustrates an LDC for the entire WECC region for several PV penetration scenarios in 2007. The load duration curve shapes for California and Colorado are quite similar, with only the magnitude of the load changing.

\footnotetext{
${ }^{3}$ One counter to this issue is the fact that only hourly data are used. Hourly data will tend to filter out such phenomena as passing clouds. However, production cost models are typically run on hourly intervals and may not capture some of the dynamic aspects of intra-hour variations of PV output.
} 


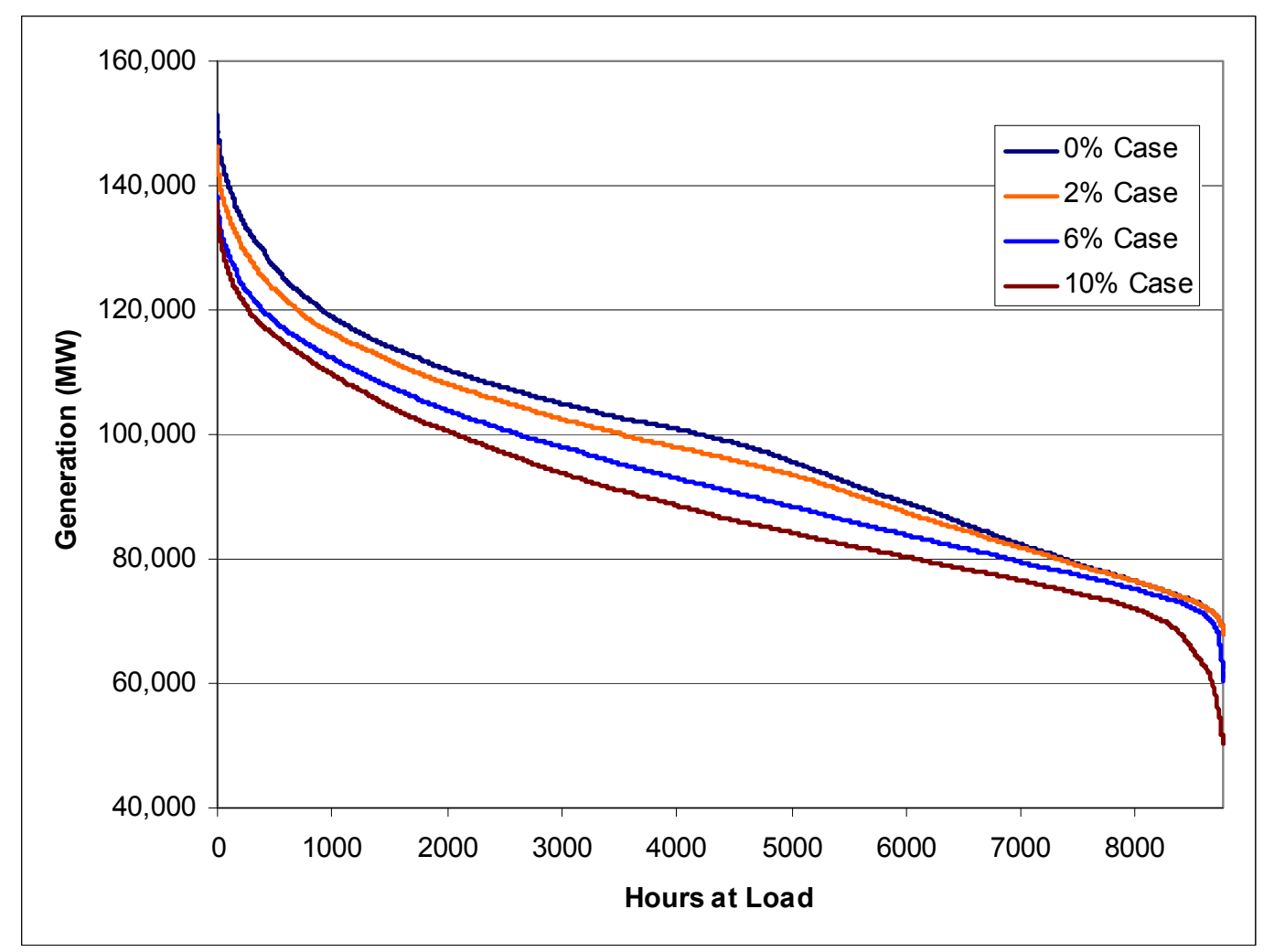

Figure 10. Load Shapes in WECC with Various PV Penetration Scenarios

Among the more noticeable features in Figure 10 is the reduction in annual minimum load that occurs in high penetration. This implies that at high penetration, $\mathrm{PV}$ will begin to offset "baseload" generation [9].

Because the future year scenarios (2015 and 2020) simply grow the 2003 load, the load shape impacts of PV are identical. This assumes that there are no long-term changes in solar output due to climate, and that electricity usage patterns stay constant over time. Sensitivities to these assumptions may be evaluated in future analysis.

\subsection{Avoided Generation}

As previously discussed, PROSYM dispatches the entire Western Interconnect and optimally dispatches the entire power plant fleet. The generation in individual areas can be isolated to examine the changes in power plant dispatch. Generators of a common type in each of the study regions (California, Colorado, and WECC as a whole) were grouped to examine PV impacts on the various generator types. The net generation within a transmission area can also be compared to the load. This establishes the net import and export of electricity. While it is not possible to track the origin and destination of every unit of energy, looking at net imports is useful, especially when the remainder of the system can be characterized. 


\subsubsection{Avoided Generation in California}

Figure 11 and Figure 12 show simulated generation for California in a summer and winter day in 2007 for each PV penetration scenario (1\% is omitted for clarity). In both cases, offset generation is primarily from combined-cycle generations, with some reduction in net imports at high penetration.

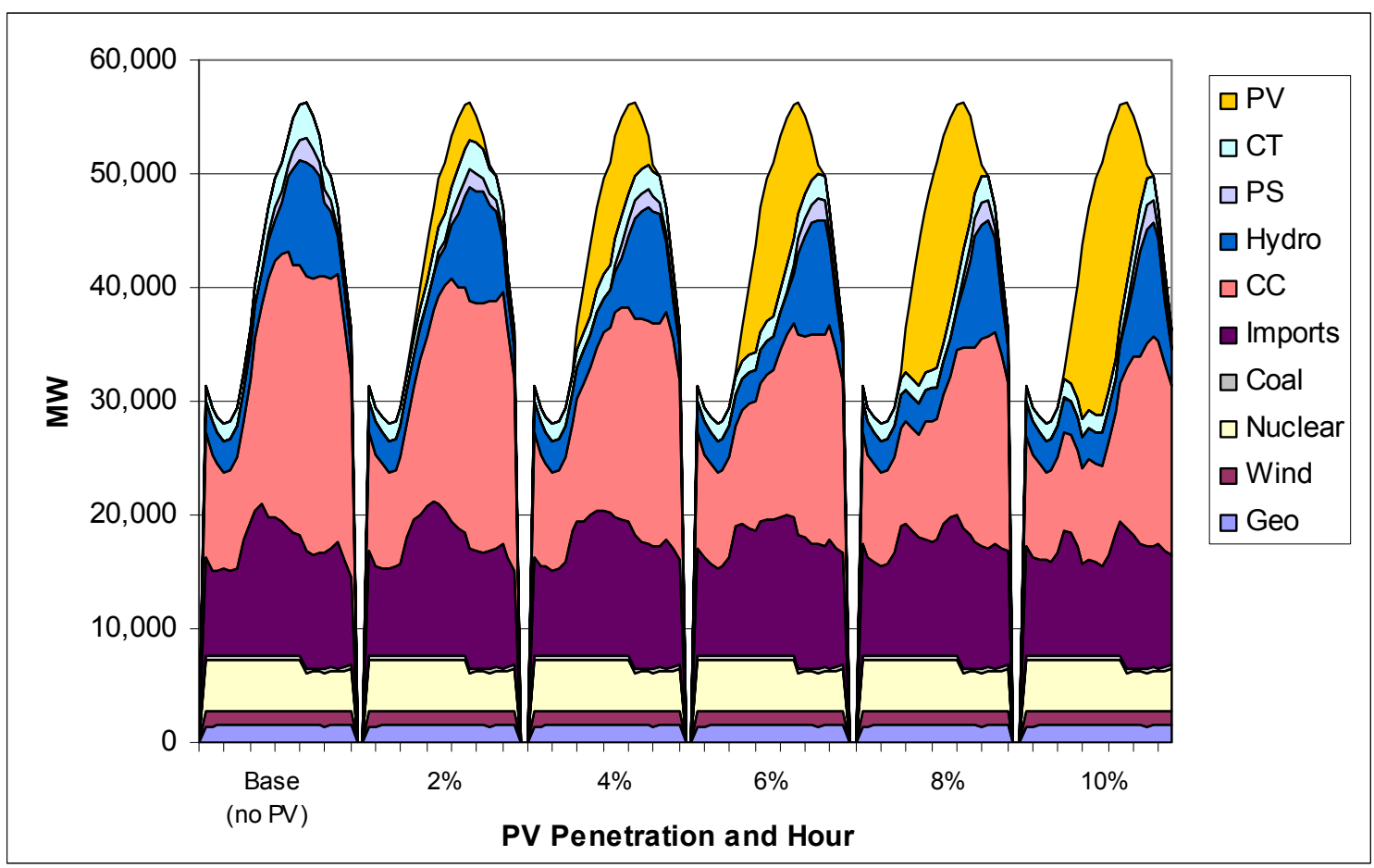

Figure 11. Simulated Dispatch in California for a Summer Day in 2007 with Various PV Penetration Scenarios 


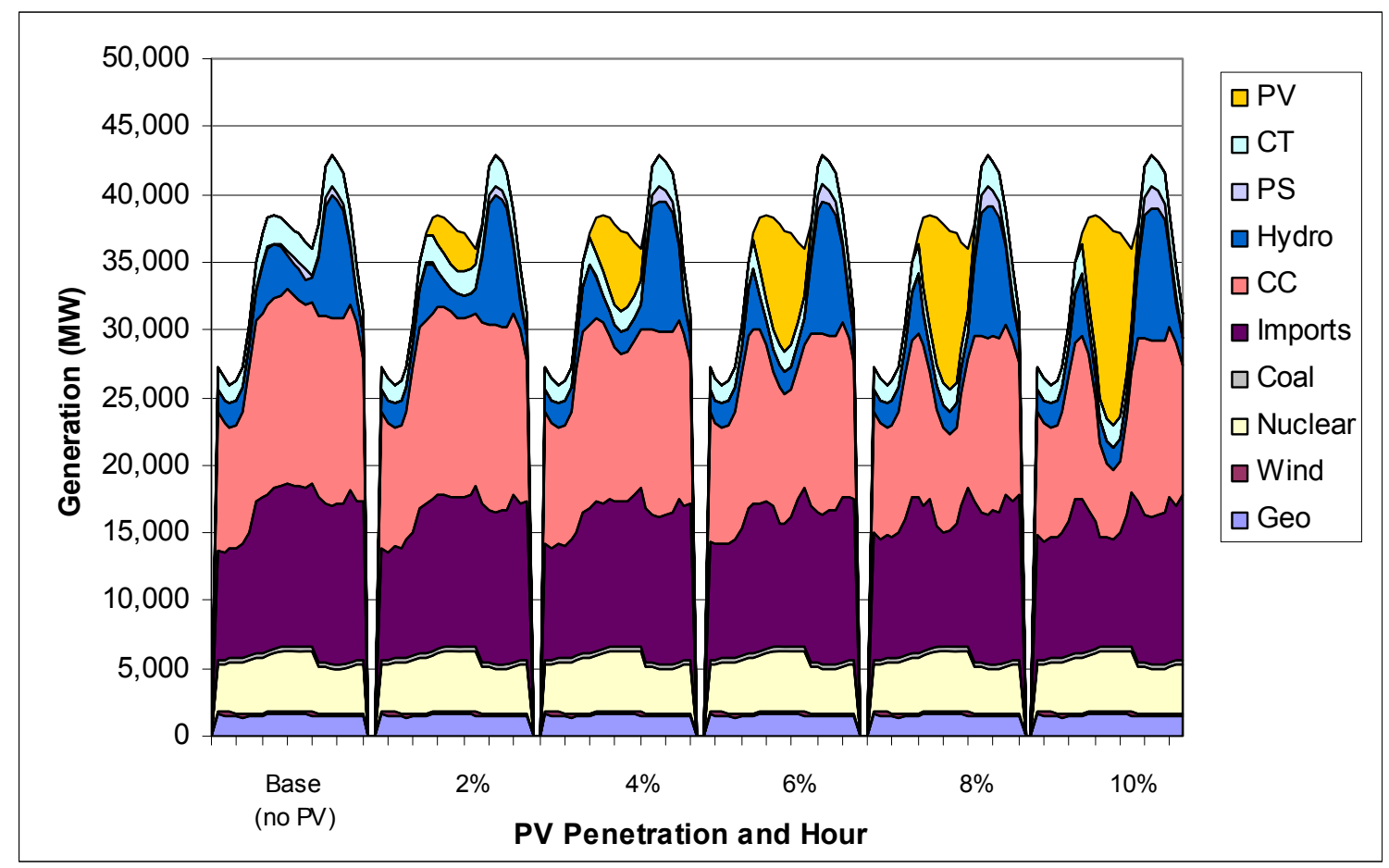

Figure 12. Simulated Dispatch in California for a Winter Day in 2007 with Various PV Penetration Scenarios

The actual mix of displaced generation is illustrated in Figure 13 and Figure 14. Figure 13 describes the total mix of ALL displaced generation at various penetration levels in the 2007 case, dominated by natural gas-fired units.

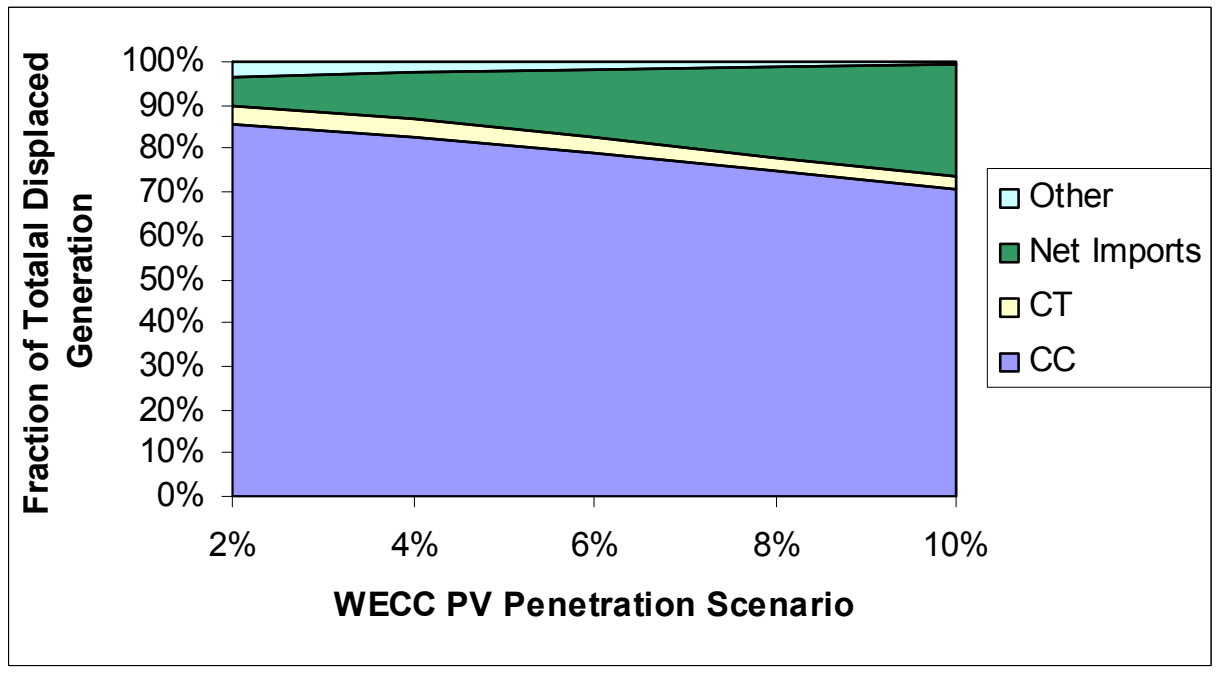

Figure 13. Mix of Displaced Generation from PV Deployed in California 
Figure 14 illustrates the incremental or marginal displaced generation in each "step" of PV installation. In the highest penetration case, going from $8 \%$ to $10 \%$ of all WECC generation from PV, nearly $50 \%$ of this incremental PV generation in California is offsetting generation outside the state of California.

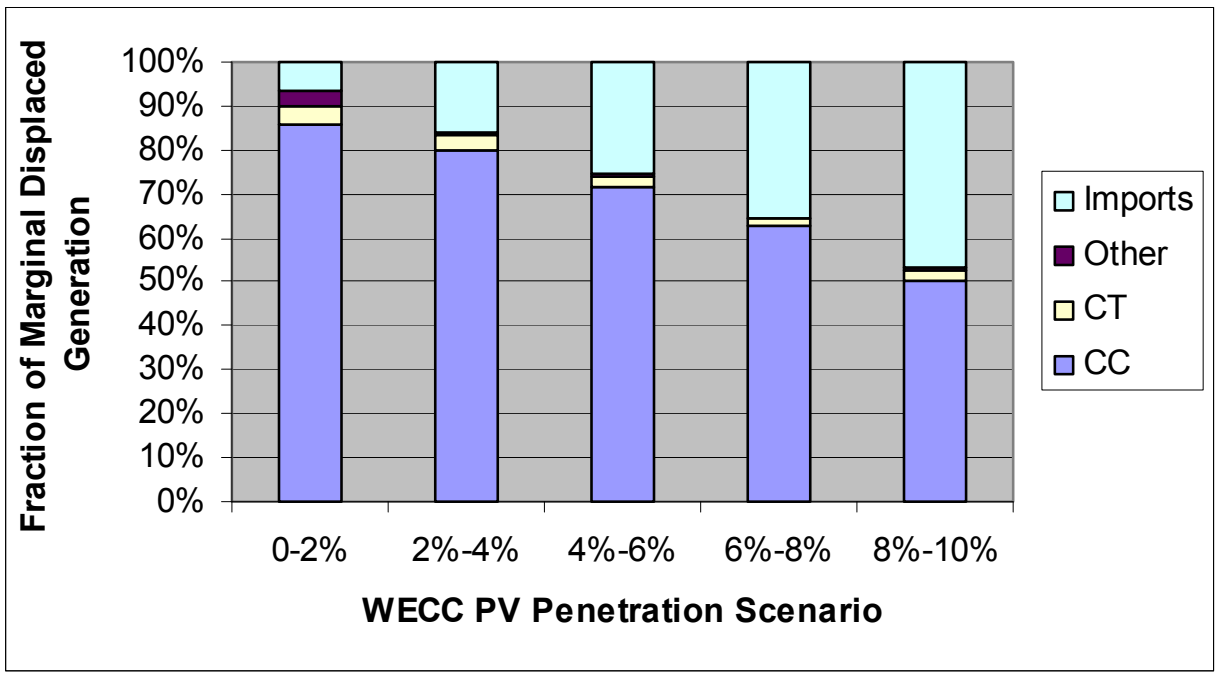

Figure 14. Mix of Incremental Displaced Generation from PV Deployed in California

\subsubsection{Avoided Generation in Colorado}

Figure 15 and Figure 16 illustrate simulated dispatch scenarios for Colorado. Compared to California, Colorado imports a much lower fraction of its electricity, and also relies more heavily on coal.

Figure 15 illustrates a spring day, demonstrating the fact that Colorado meets most of its baseload demand from coal. Up to about the 4\% to $6 \%$ scenario, PV displaces mostly CC and imports on this day. Beyond this point, PV begins to displace coal generation. During certain hours, imports are completely displaced, and the state becomes a net exporter of electricity. (While the graph implies that coal and wind are being exported, we are not explicitly tracking imports and exports at the plant level, and the origin of the exports cannot be explicitly identified.) 


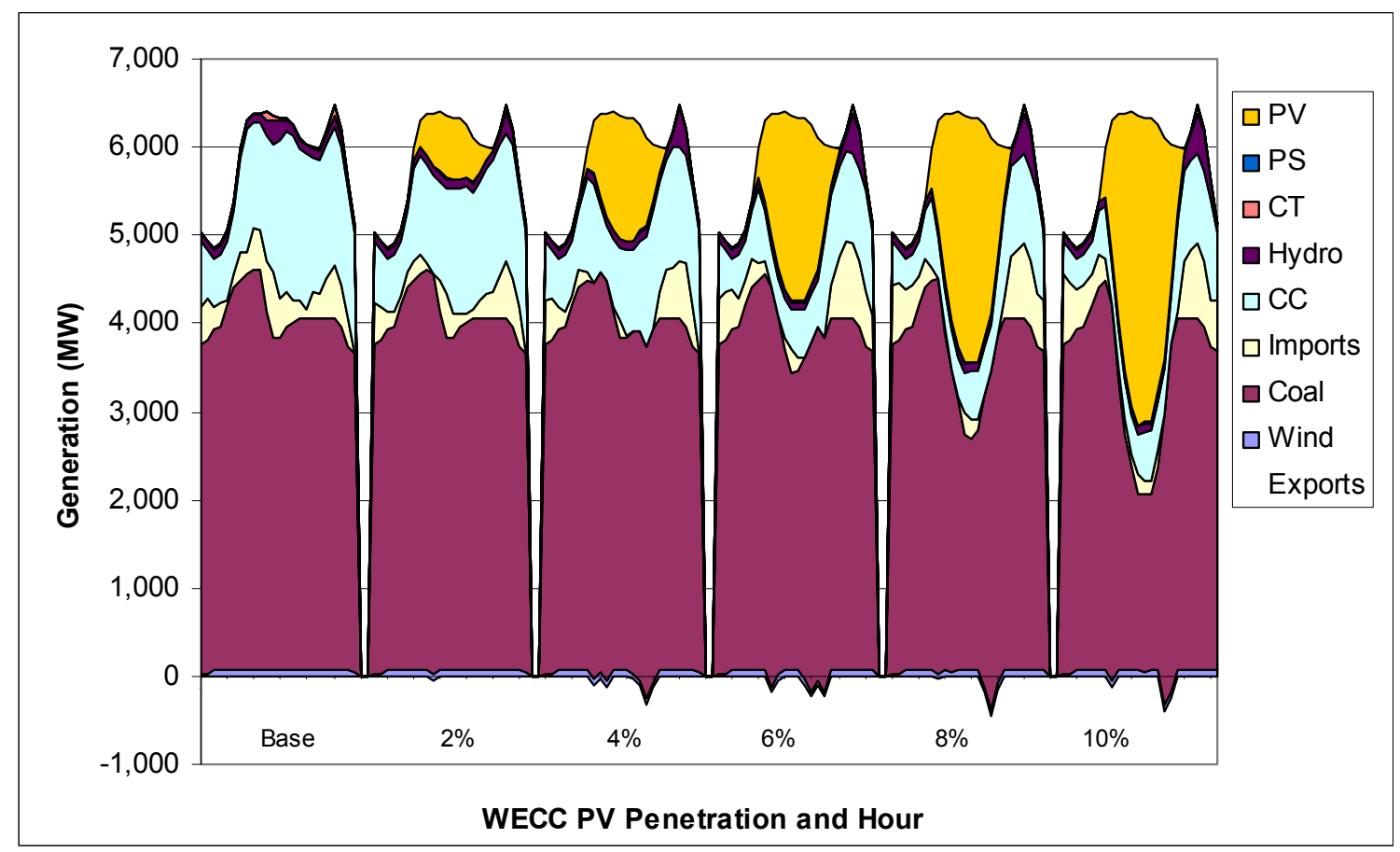

Figure 15. Simulated Dispatch in Colorado for a Spring Day in 2007 with Various PV Penetration Scenarios

Figure 16 provides the results of a summer day simulation. The greater baseload demand results in even less coal displacement, and most PV generation displaces natural gas-fired generators. As before, the area of negative generation represents periods where there is a net export (imports are negative) of electricity from the state. 


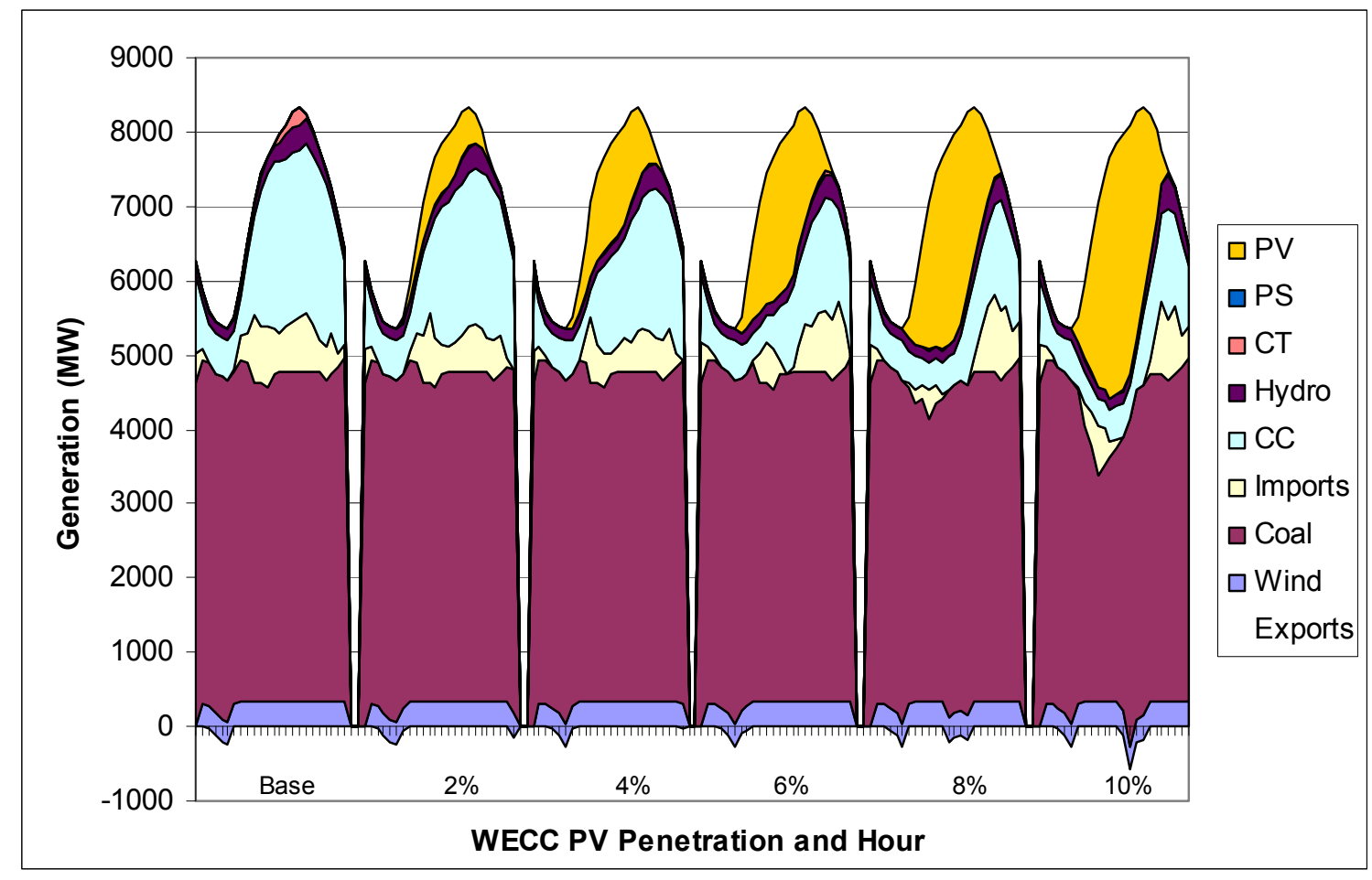

Figure 16. Simulated Dispatch in Colorado for a Summer Day in 2007 with Various PV Penetration Scenarios

Figure 17 illustrates the total fractional mix of displaced generation.

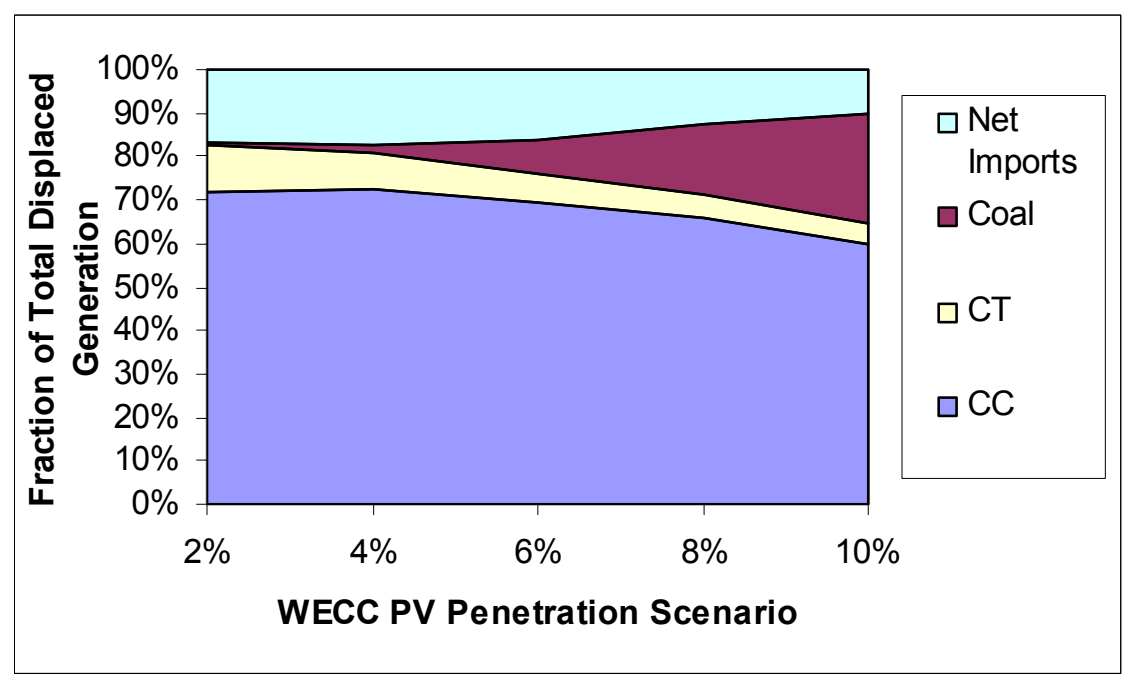

Figure 17. Mix of Total Displaced Generation from PV Deployed in Colorado

Figure 18 illustrates the incremental fractional mix of displaced generation. In the $8 \%$ to $10 \%$ WECC penetration scenario, about $60 \%$ of this incremental PV generation in Colorado is offsetting coal-fired generation. 


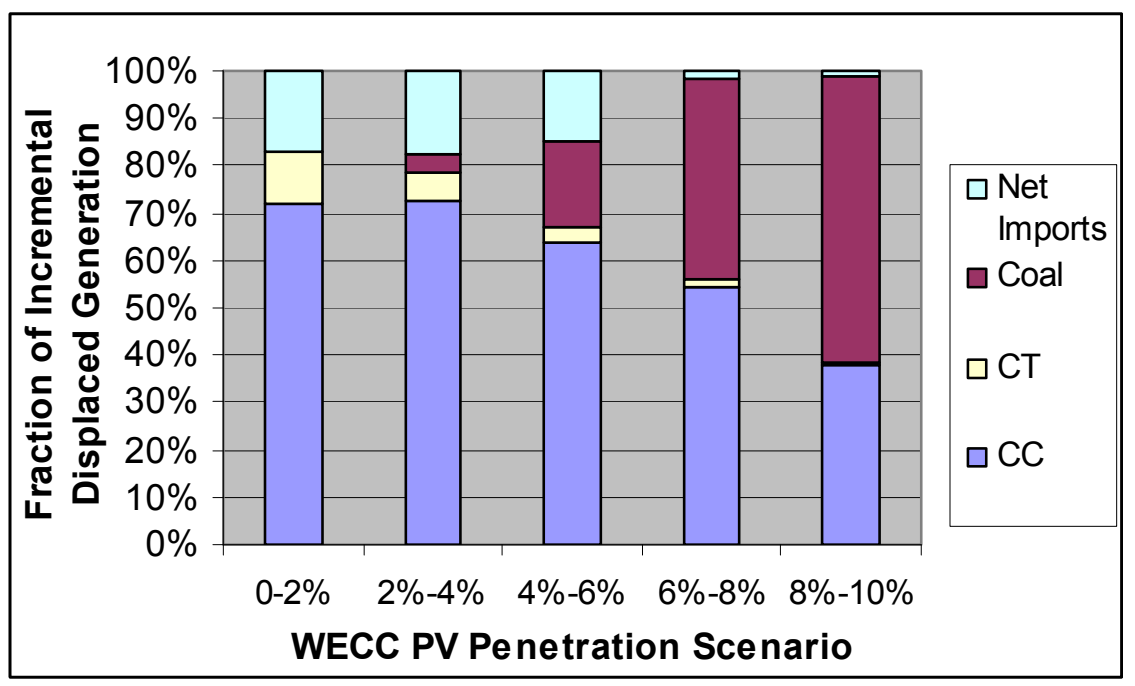

Figure 18. Mix of Incremental Displaced Generation from PV Deployed in Colorado

\subsubsection{Avoided Generation in WECC}

Figure 19, Figure 20, and Figure 21 illustrate the representative impacts over the entire WECC Region (including California and Colorado) for representative winter, spring, and summer days.

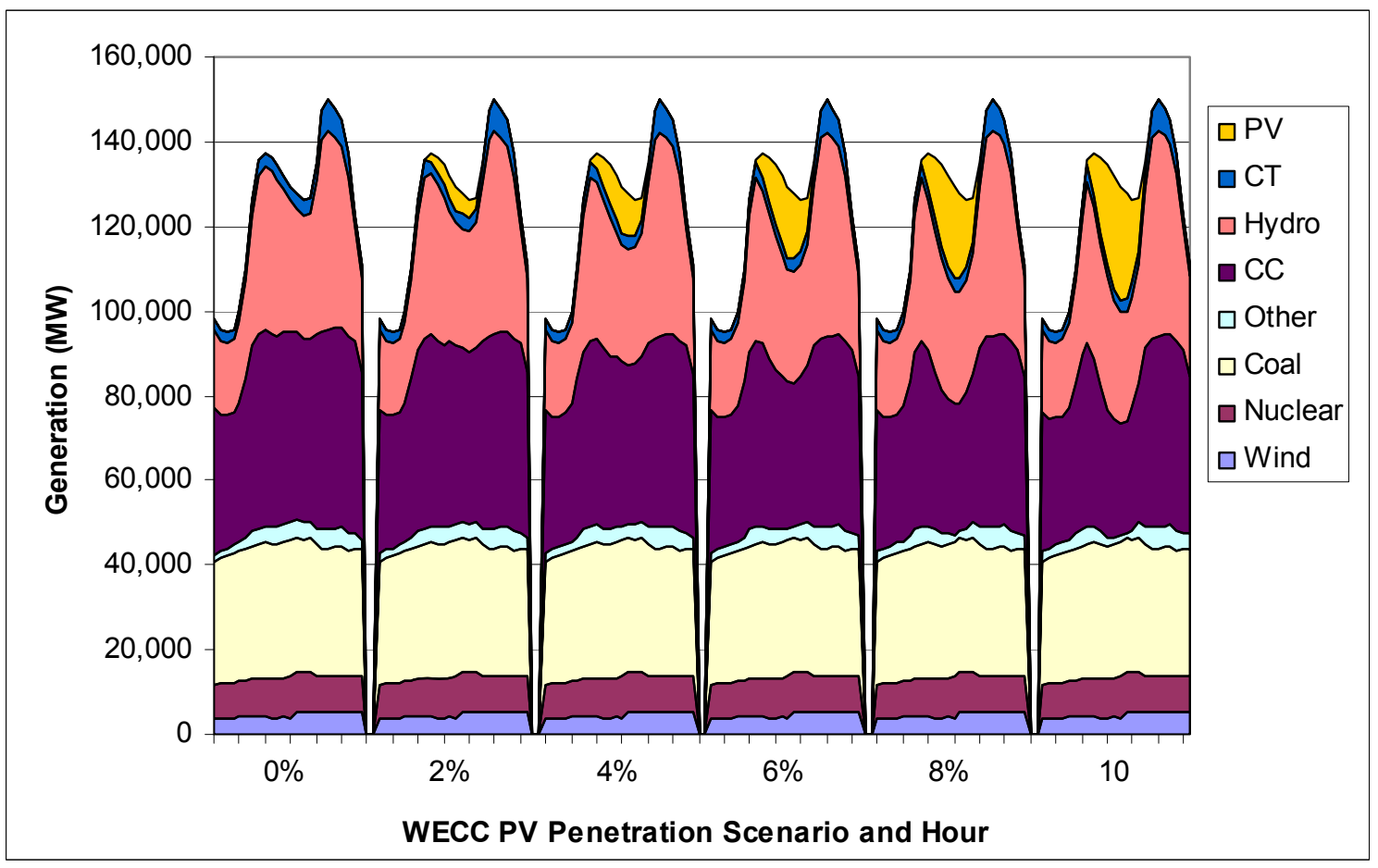

Figure 19. Simulated Dispatch in WECC for a Winter Day in 2007 with Various PV Penetration Scenarios 


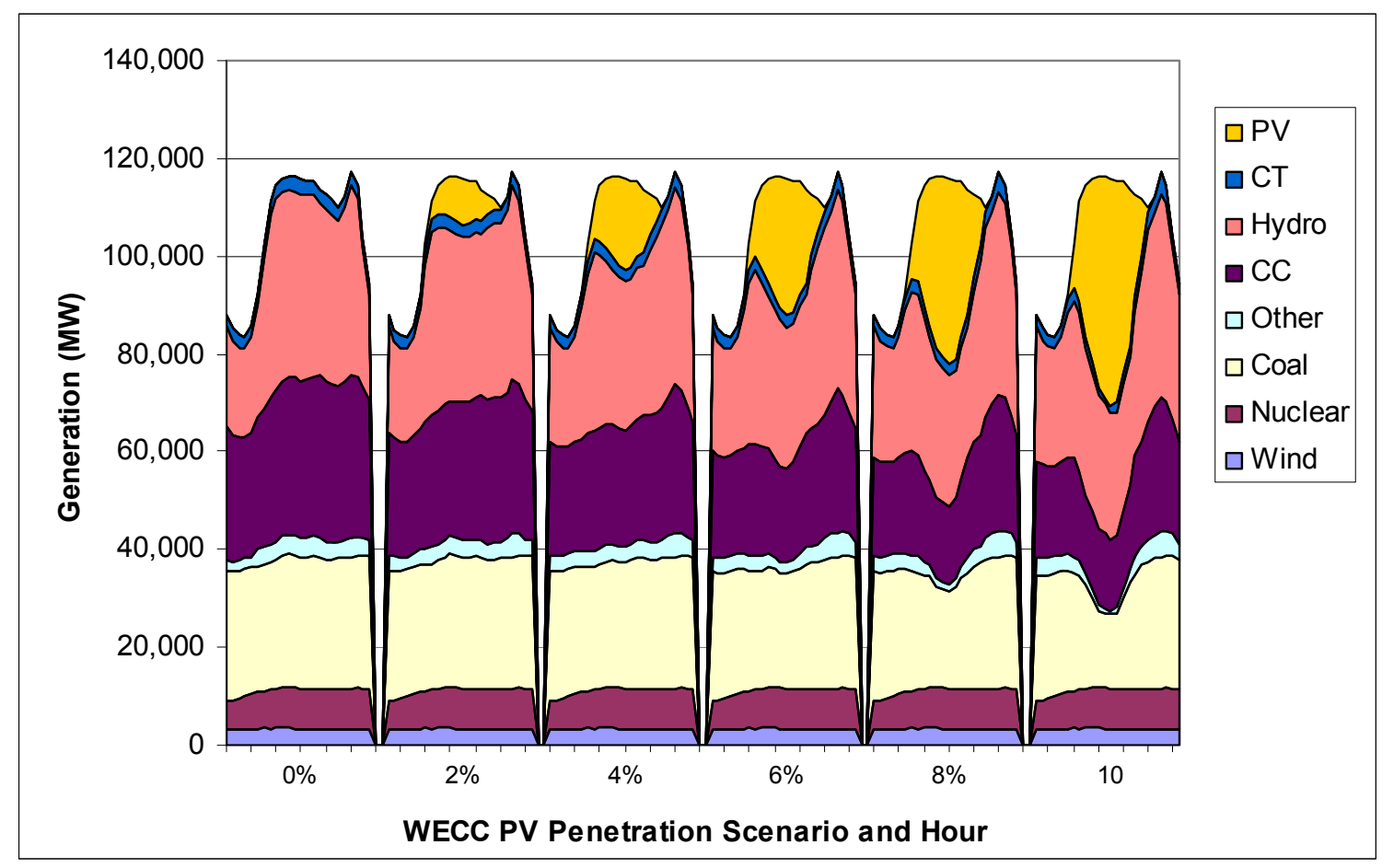

Figure 20. Simulated Dispatch in WECC for a Spring Day in 2007 with Various PV Penetration Scenarios

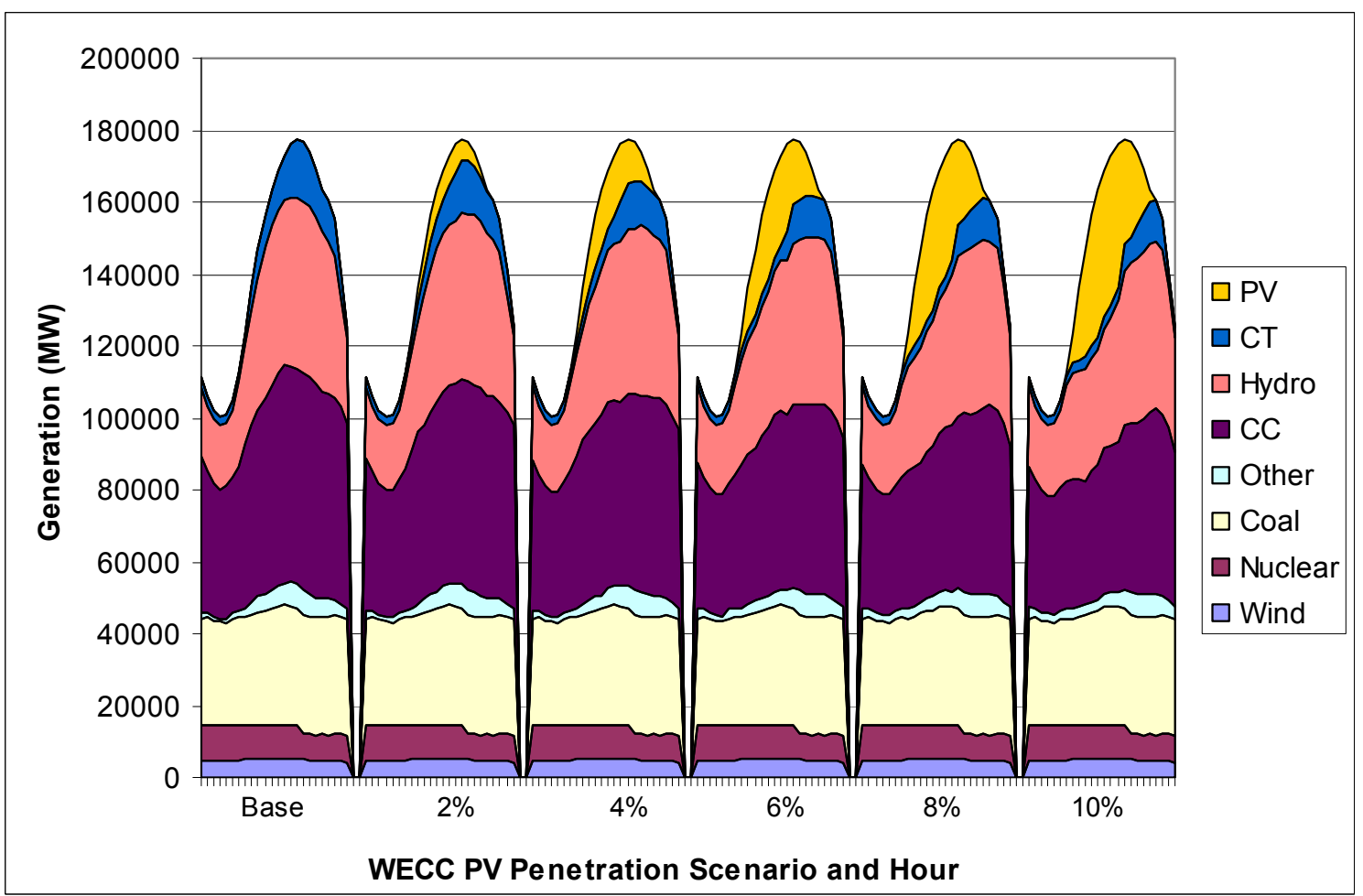

Figure 21. Simulated Dispatch in WECC for a Summer Day in 2007 with Various PV Penetration Scenarios 
The previous simulations indicate that taken as a whole, the assumed mix of PV locations results in mostly displacement of gas-fired generators. Figure 22 illustrates that at a $10 \%$ penetration, more than $85 \%$ of the total expected offset generation will occur from natural gas-fired generators. Figure 23 illustrates the incremental offset generation.

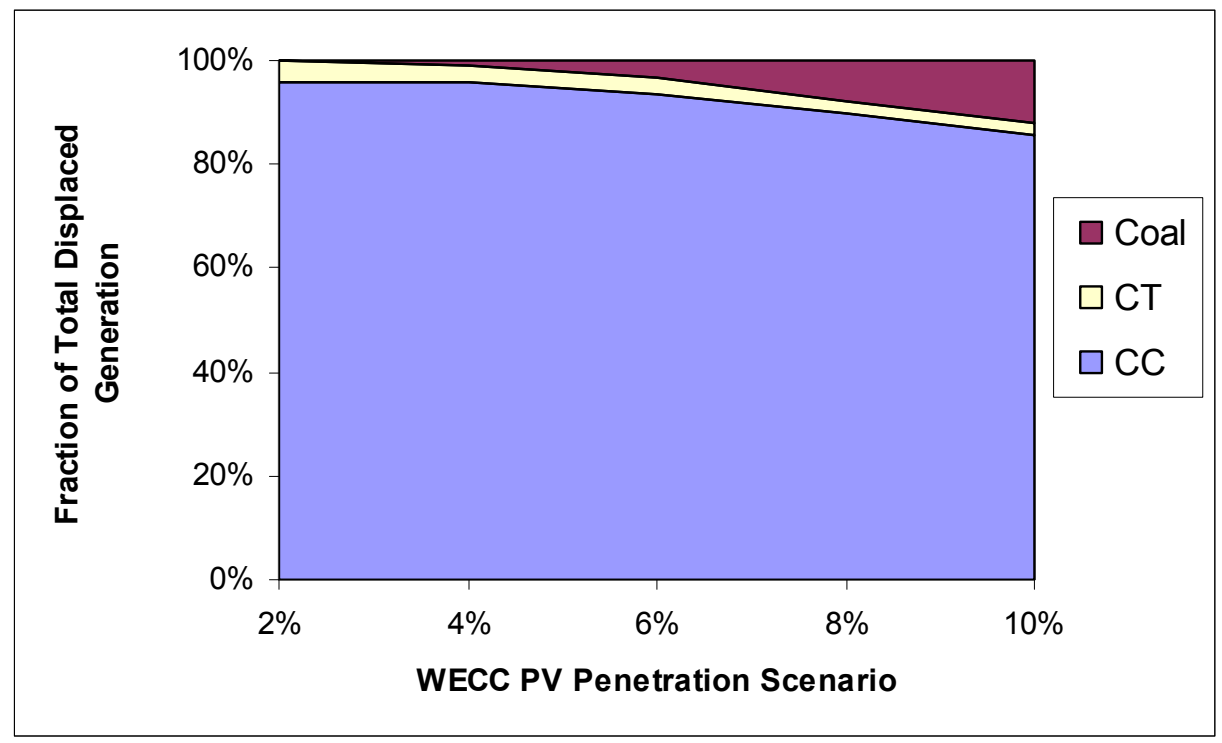

Figure 22. Mix of Total Displaced Generation from PV Deployed in WECC

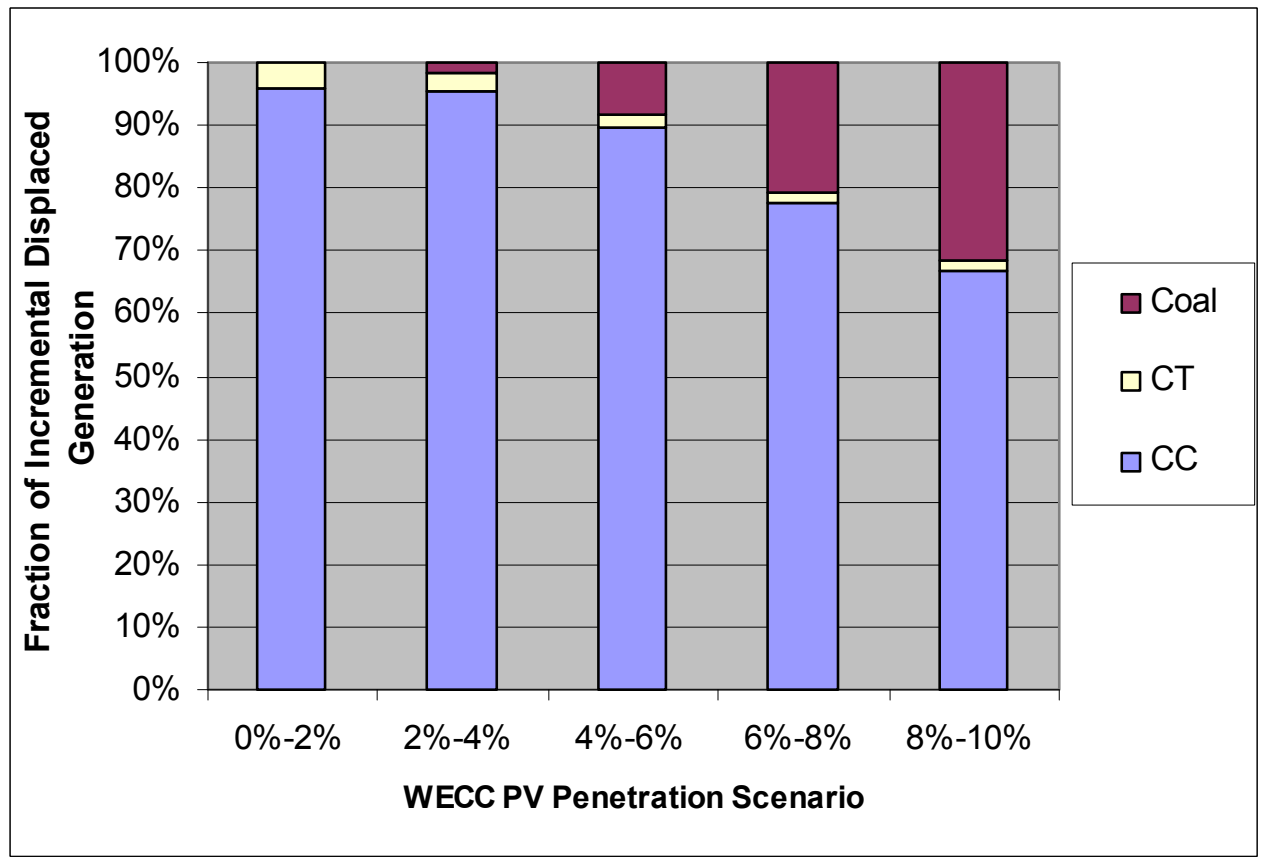

Figure 23. Mix of Incremental Displaced Generation from PV Deployed in WECC 


\subsection{Avoided Fuel Use}

The avoided generation estimates can be translated into avoided fuel, and produce a "fuel content" for a kilowatt-hour ( $\mathrm{kWh}$ ) of electricity generated by a PV system in various regions within WECC. In addition to the variation in generator types, the model simulates the effect of part-load operation. If PV increases the amount of power plant cycling, this may result in higher average heat rates for plants following the variation in output from distributed $\mathrm{PV}$ and a corresponding decrease in offset emissions rates.

\subsubsection{Avoided Fuel Use in California}

Figure 24 illustrates the average gas displacement rate for PV generation in the state of California. Three lines are shown: the displacement rate for PV when offsetting CT generation, $\mathrm{CC}$ generation, and the weighted average of both (dominated by CCs as demonstrated in Figure 13). It is important to note that this offset applies only to the fraction of generation that effectively "stays" in California. These results can be combined with the fraction of in-state generation offset by PV in Figure 13.

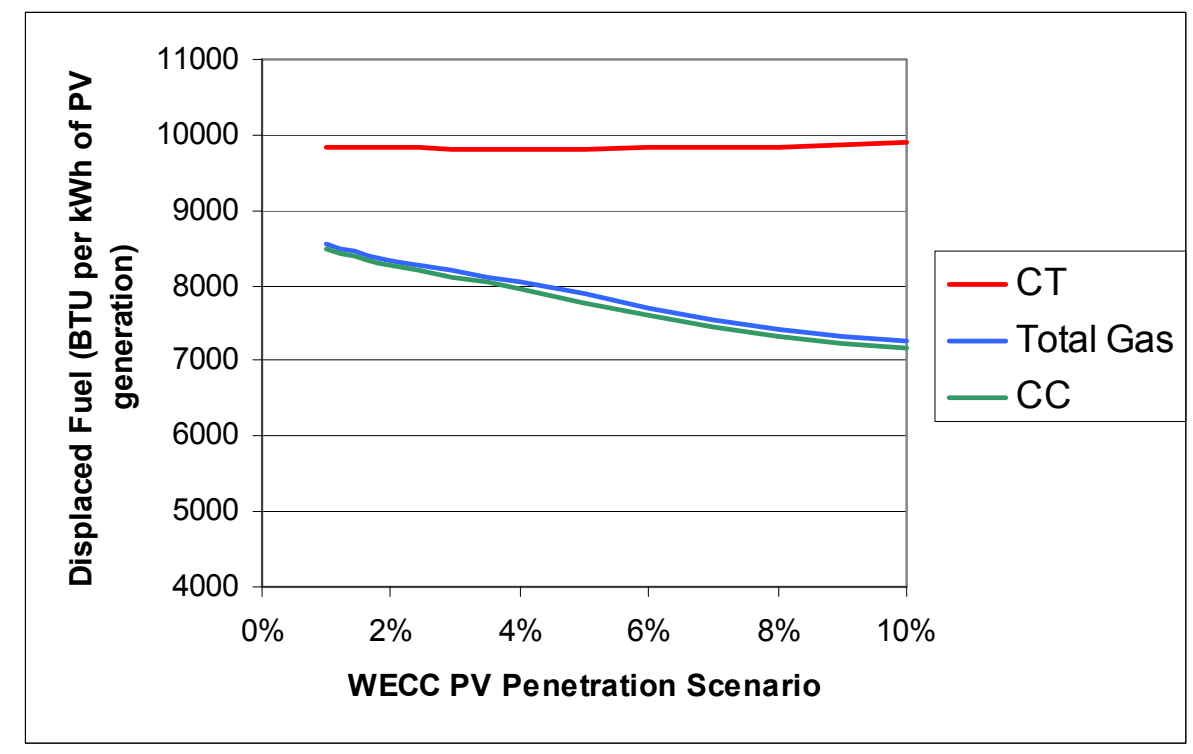

Figure 24. Average Natural Gas Fuel Displacement from PV Deployed in California and Offsetting California Generation

Figure 25 illustrates the marginal displacement rate for California generation. As before, this only applies to the fraction of PV generation that displaces in-state generation as estimated in Figure 13. 


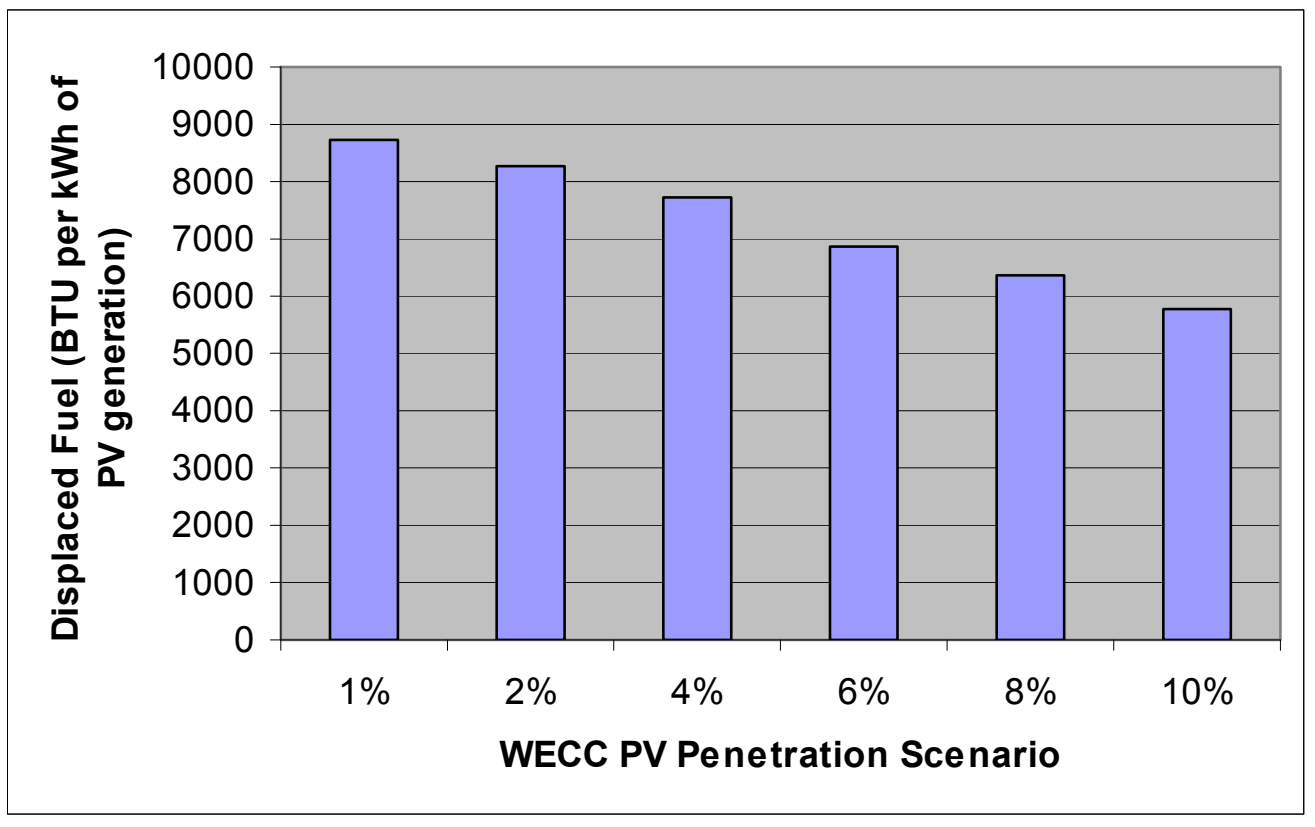

Figure 25. Incremental Natural Gas Fuel Displacement from PV Deployed in California and Offsetting California Generation

The decrease in fuel benefits illustrated in Figure 24 and Figure 25 shows not only the increased displacement of more efficient generators as a function of penetration, but also the impacts of increased cycling. Figure 26 demonstrates the overall increase in gas unit heat rates that result from the increased cycling.

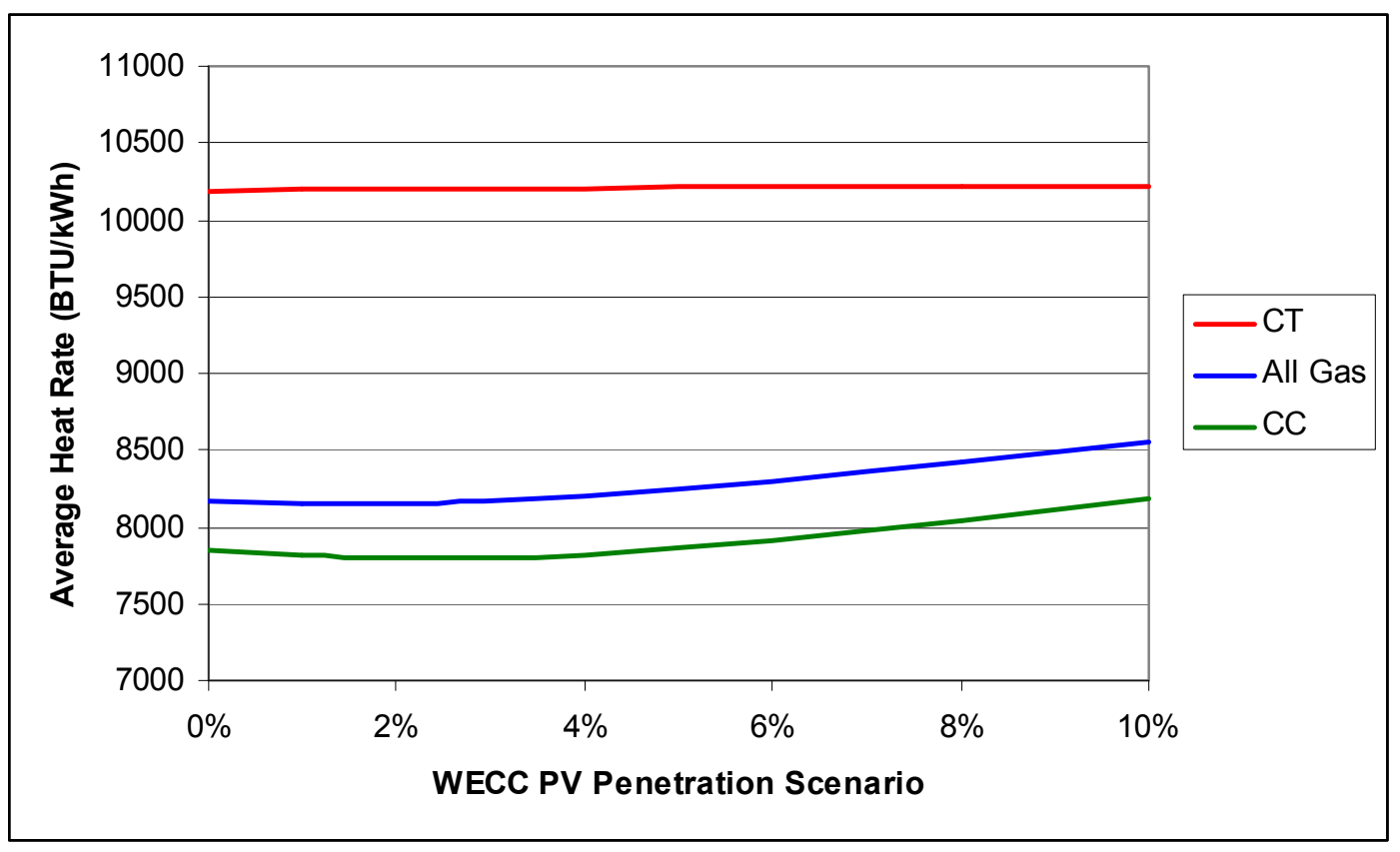

Figure 26. Average Heat Rates of California Natural Gas Generators Resulting from PV Load Following 


\subsubsection{Avoided Fuel Use in Colorado}

Within Colorado, both natural gas and coal is displaced by PV. Figure 27 illustrates the fuel offset rate for each of the plant types displaced by PV.

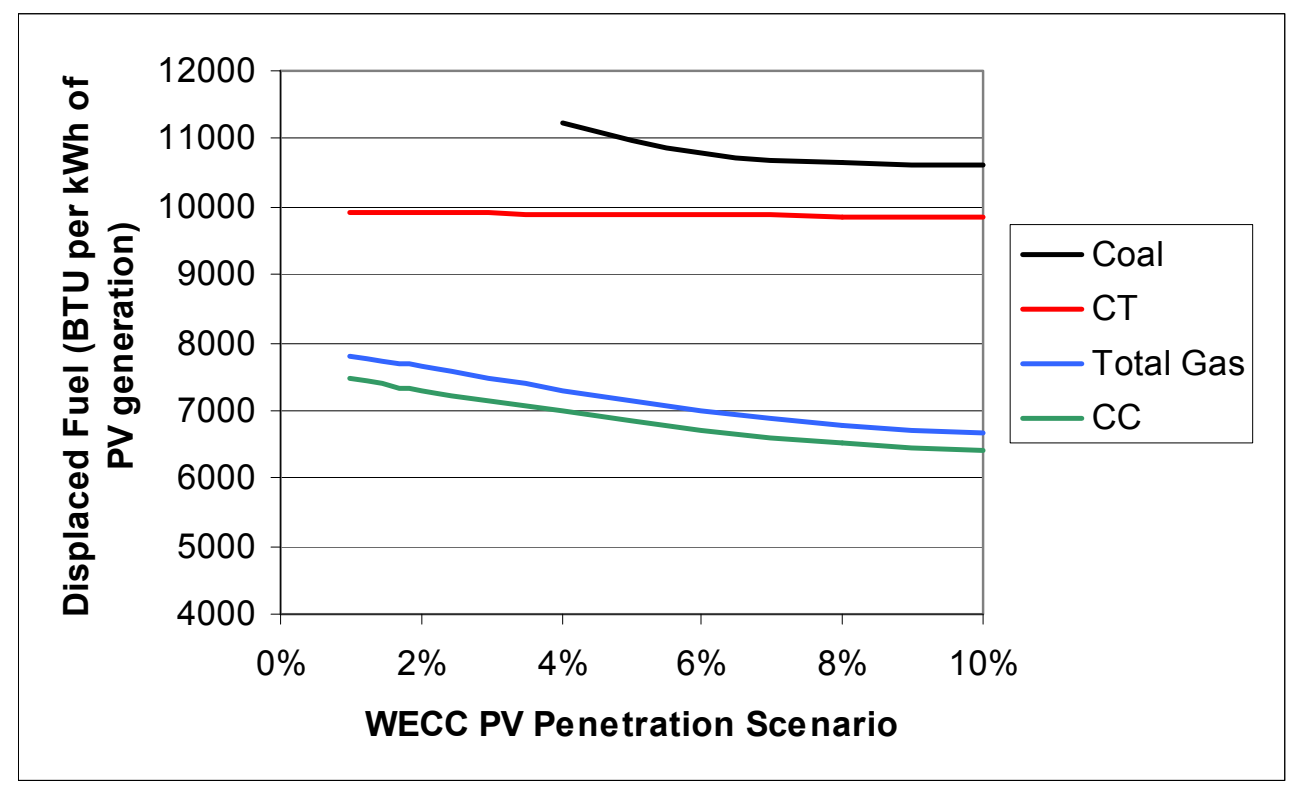

Figure 27. Average Fuel Displacement Rates from PV Deployed in Colorado and Offsetting Colorado Generation

Using the estimated displacement mix of in-state generation from Figure 17 it is possible to estimate the overall average fuel displacement from $1 \mathrm{kWh}$ of PV generation used within Colorado. Figure 28 illustrates the average total fuel displacement from in-state PV generation, while Figure 29 illustrates incremental fuel displacement. 


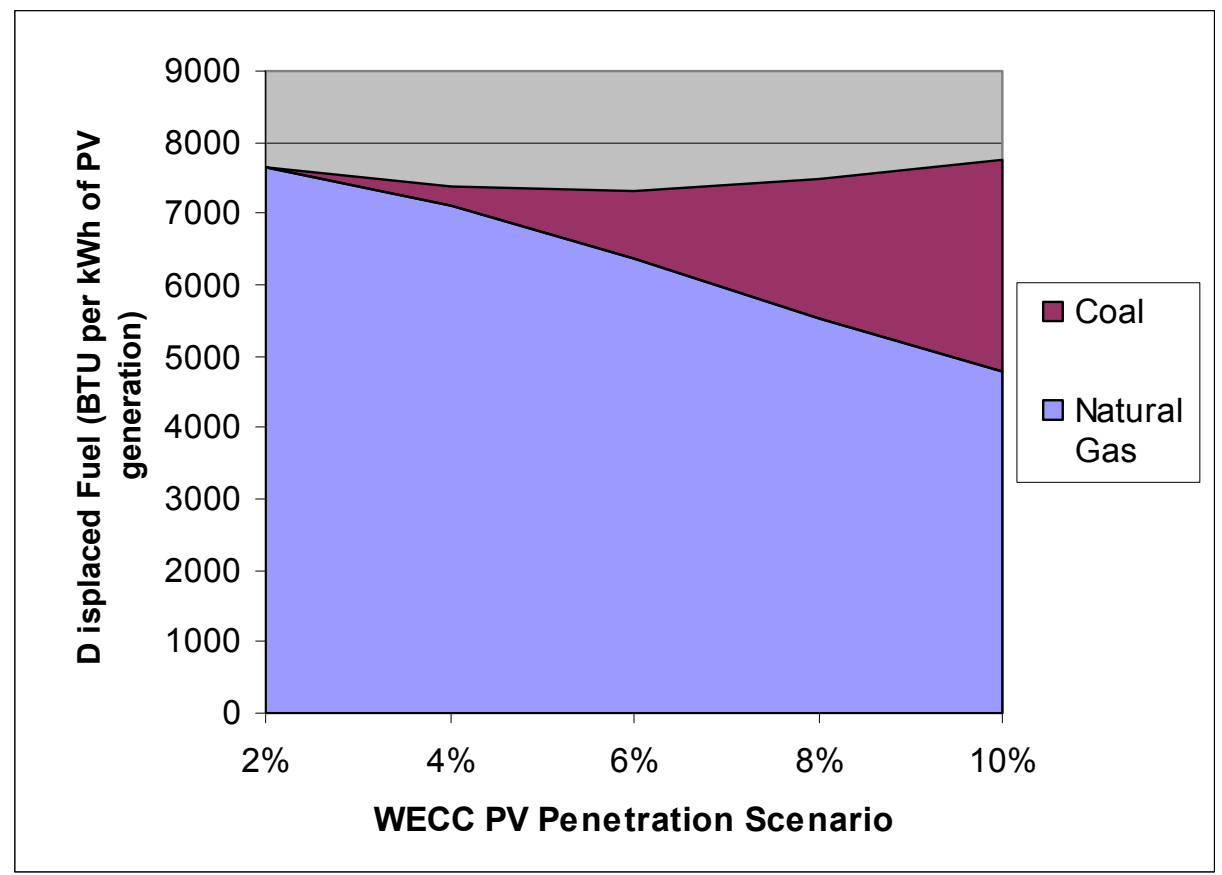

Figure 28. Total Average Fuel Displacement from PV Deployed in Colorado and Offsetting Colorado Generation

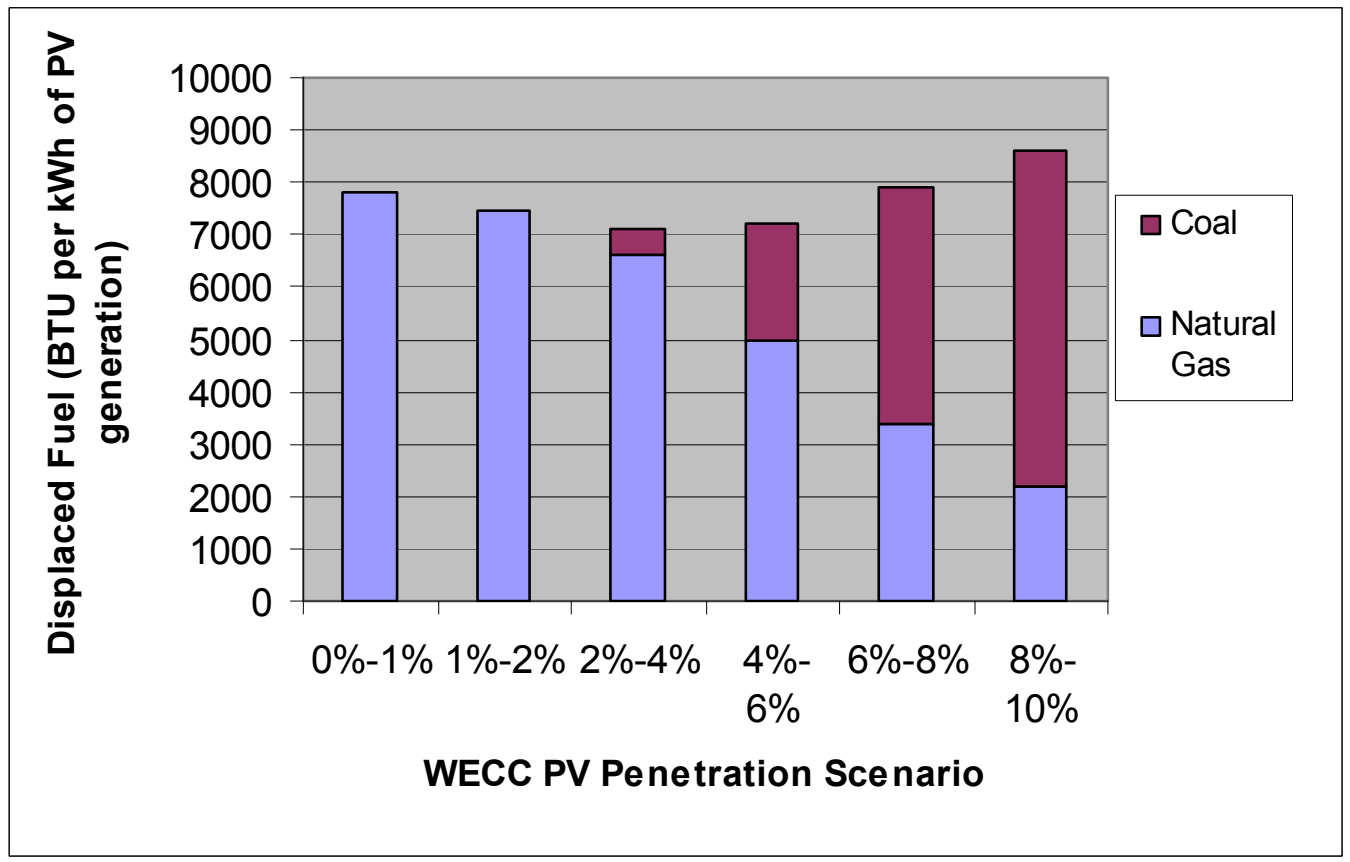

Figure 29. Incremental Fuel Displacement from PV Deployed in Colorado and Offsetting Colorado Generation 


\subsubsection{Avoided Fuel Use in WECC}

The overall fuel displacement rate within the entire WECC region is illustrated in Figure 30 and Figure 31.

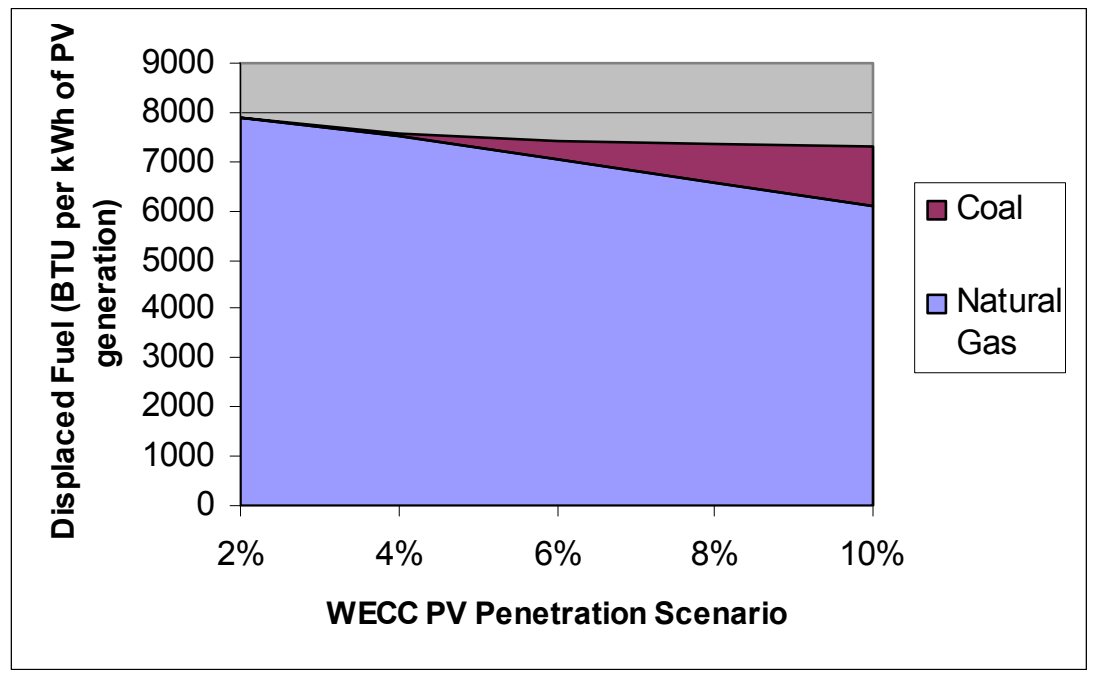

Figure 30. Total Average Fuel Displacement from PV Deployed in WECC

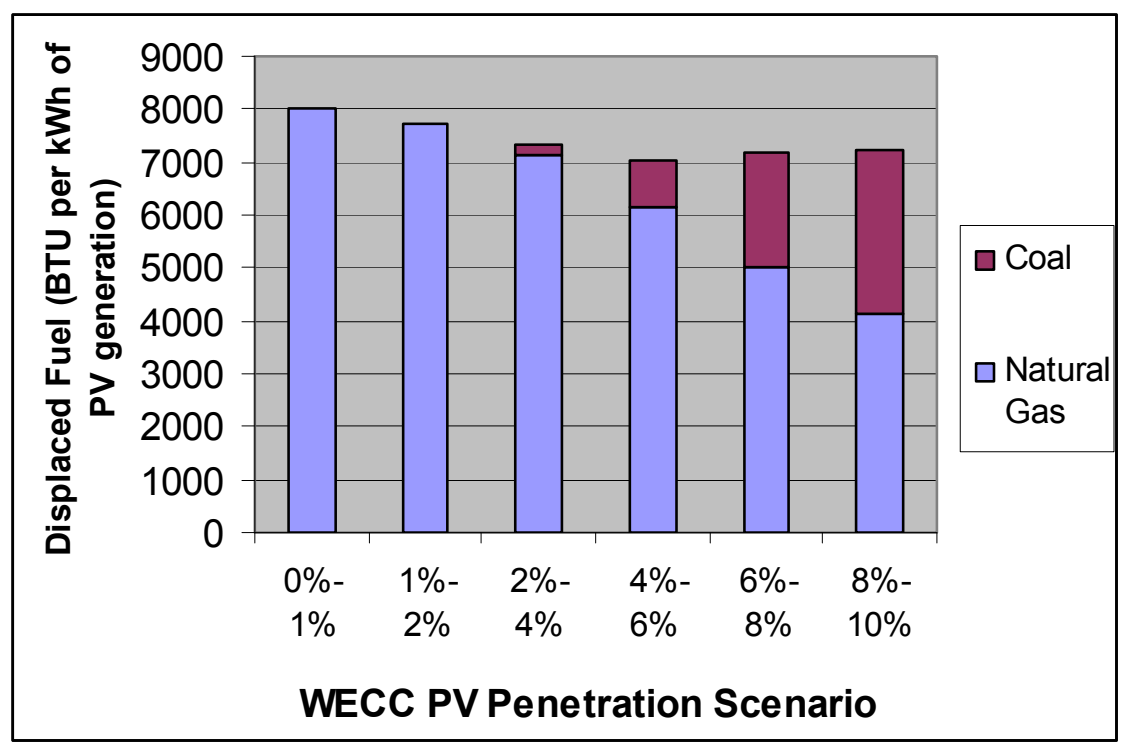

Figure 31. Incremental Fuel Displacement from PV Deployed in WECC

\subsection{Avoided Emissions}

Estimates were produced for the avoided emissions of $\mathrm{CO}_{2}, \mathrm{NO}_{\mathrm{x}}$ and $\mathrm{SO}_{2}$. 


\subsubsection{Avoided Emissions in California}

Figure 32 illustrates the $\mathrm{CO}_{2}$ emissions offset rate in California. Both marginal and incremental offset rates are shown. The decrease in emissions benefits as PV penetration increases is due to both the reduced displacement of less efficient generators, and increased fuel use associated with power plant cycling. As before, these rates apply only to the portion of PV generation that offsets California generation.

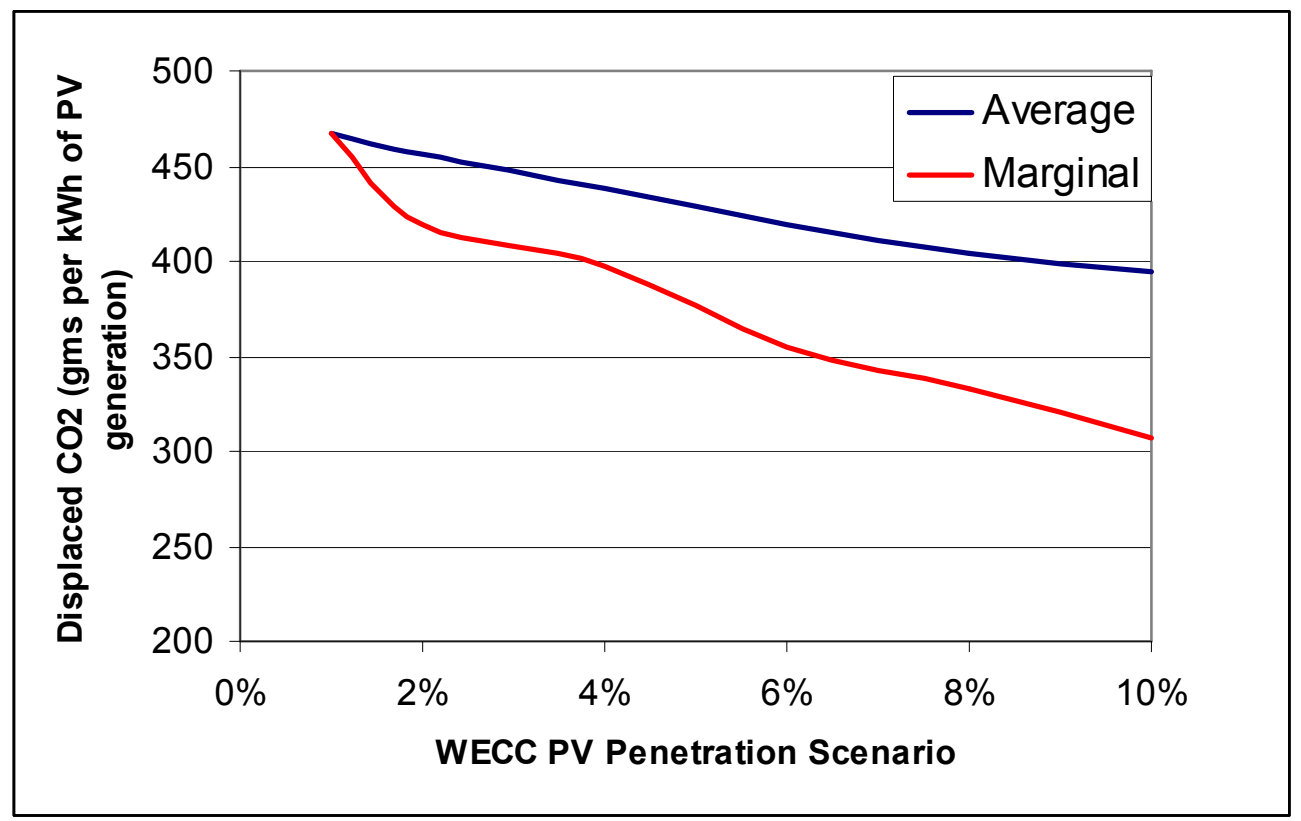

Figure 32. Average and Marginal $\mathrm{CO}_{2}$ Emissions Displacement from PV Deployed in California and Offsetting California Generation

$\mathrm{SO}_{2}$ emissions are primarily associated with coal combustion. Because there is very little coal-based electricity generation in California, only $\mathrm{NO}_{\mathrm{x}}$ emissions were evaluated. Figure 33 estimates the $\mathrm{NO}_{\mathrm{x}}$ offset rate for $\mathrm{PV}$ generation that reduces in-state generation. There is initially a small decrease in the $\mathrm{NO}_{\mathrm{x}}$ offset rates as PV displaces more efficient units, then an increase resulting from the offset of oil-fired units with higher NOx emission rates. 


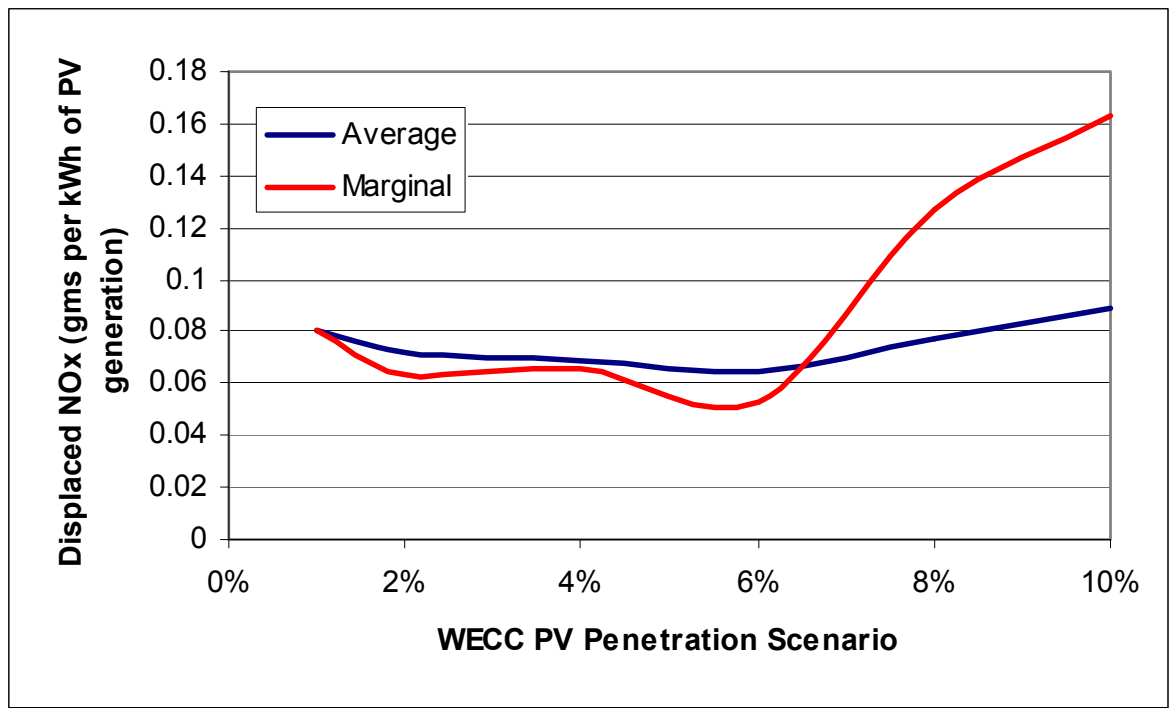

Figure 33. Average and Marginal $\mathrm{NO}_{x}$ Emissions Displacement from PV Deployed in California and Offsetting California Generation

\subsubsection{Avoided Emissions in Colorado}

Figure 34 and Figure 35 illustrate the average and marginal $\mathrm{CO}_{2}$ emissions offset rates, showing the mix of avoided emissions from both coal and natural gas plants.

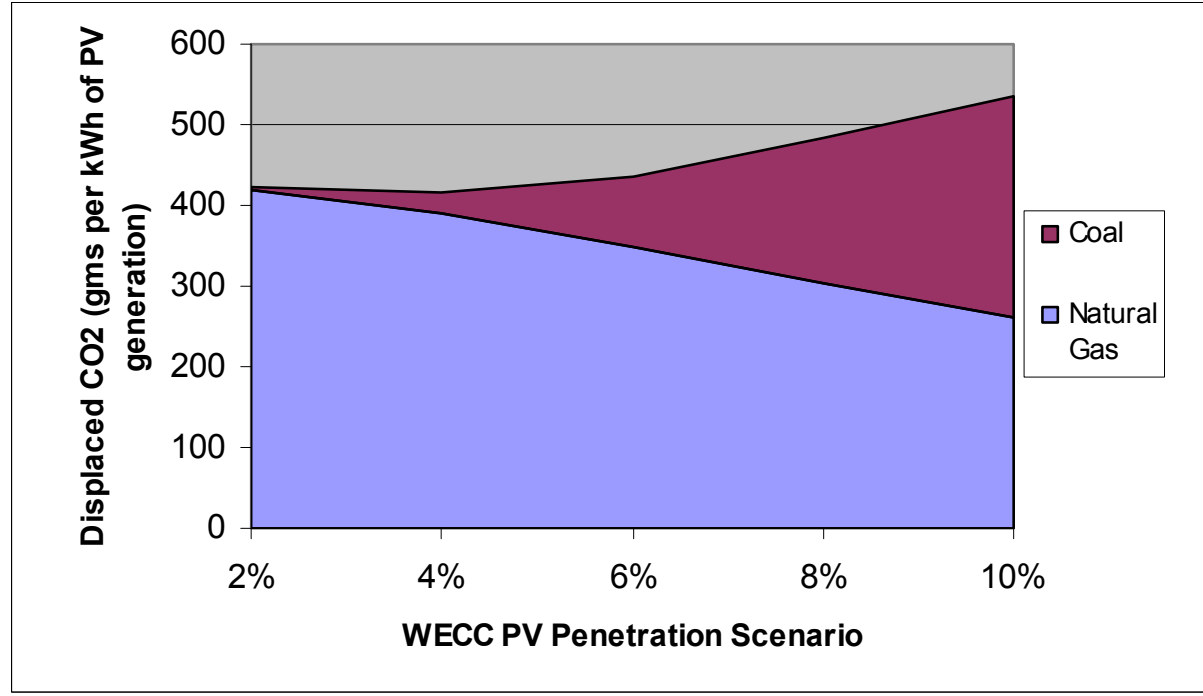

Figure 34. Total Average $\mathrm{CO}_{2}$ Emissions Displacement from PV Deployed in Colorado and Offsetting Colorado Generation 


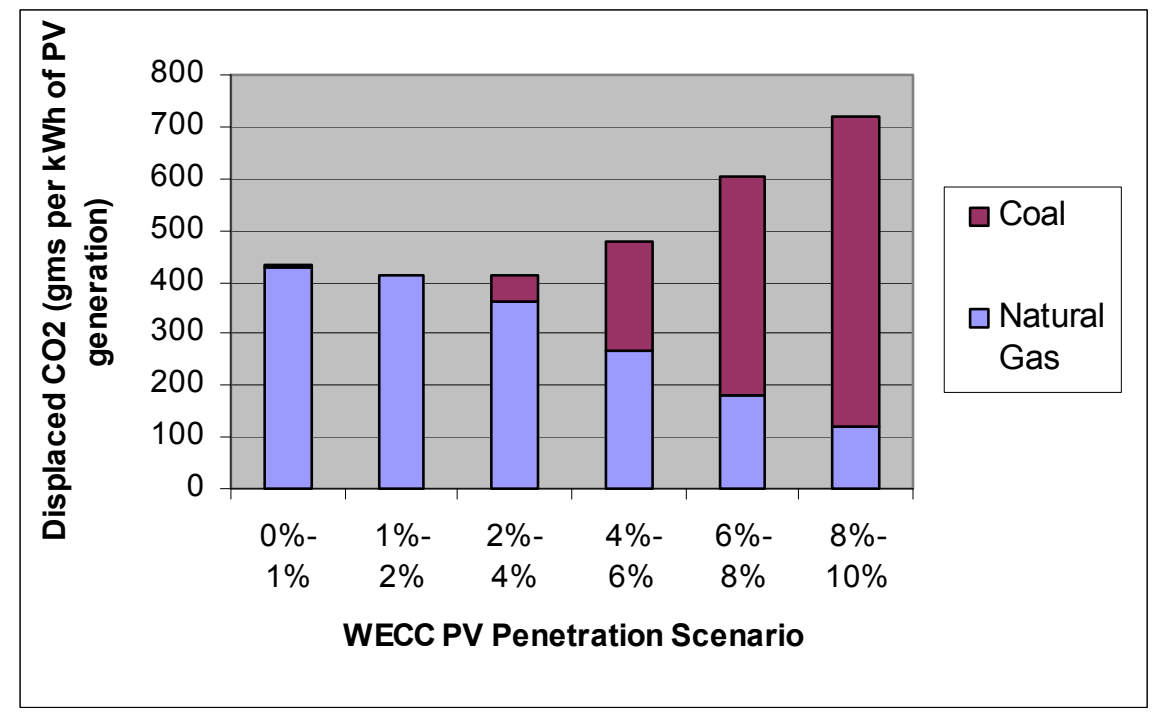

Figure 35. Incremental $\mathrm{CO}_{2}$ Emissions Displacement from PV Deployed in Colorado and Offsetting Colorado Generation

The estimated $\mathrm{NO}_{\mathrm{x}}$ and $\mathrm{SO}_{2}$ offset rates are provided in Figure 36, demonstrating the greater emissions rates associated with coal-fired generation.

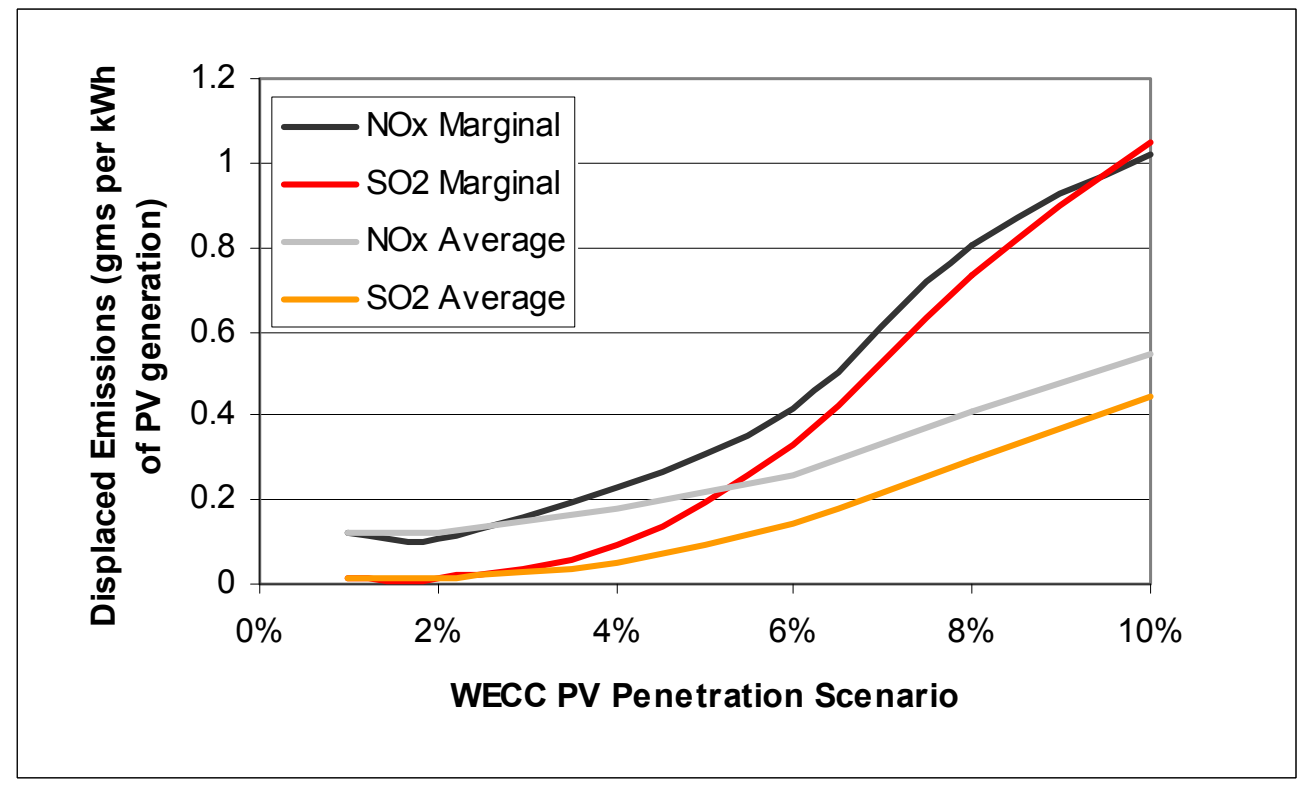

Figure 36. Average and Marginal $\mathrm{NO}_{\mathrm{x}}$ and $\mathrm{SO}_{2}$ Emissions Displacement from PV Deployed in Colorado and Offsetting Colorado Generation

\subsubsection{Avoided Emissions in WECC}

The overall $\mathrm{CO}_{2}$ emissions displacement is driven by the fuel displacement values illustrated in Figure 30 and Figure 31. The average and marginal values are provided in Figure 37. 


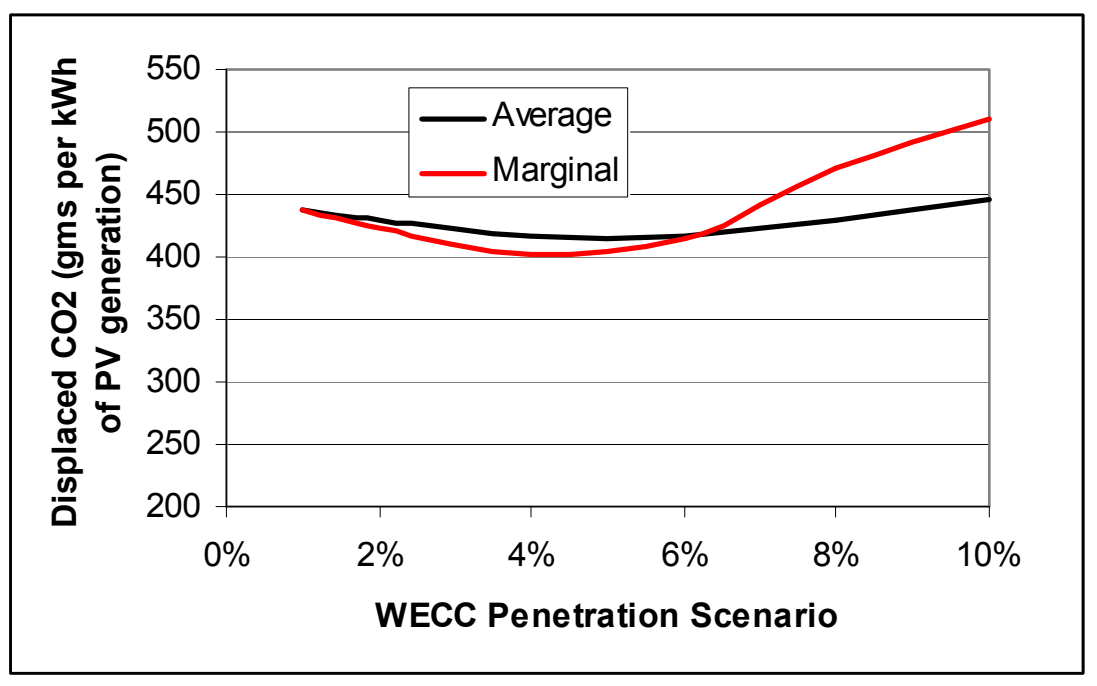

Figure 37. Average and Marginal $\mathrm{CO}_{2}$ Emissions Displacement from PV Deployed in WECC

Overall, there is a substantial variation in emissions displacement on a seasonal basis. Figure 38 illustrates the incremental $\mathrm{CO}_{2}$ emissions displacement for various penetration scenarios in each month. At low penetration, PV offsets high emissions peaking units during the summer, and more efficient combined-cycle units during the off-peak seasons. The incremental emissions rates then drop as PV starts offsetting more efficient units during all seasons. At higher penetrations (above $2 \%$ to $4 \%$ ) PV starts to offset coal units, and displaced emissions rates increase.

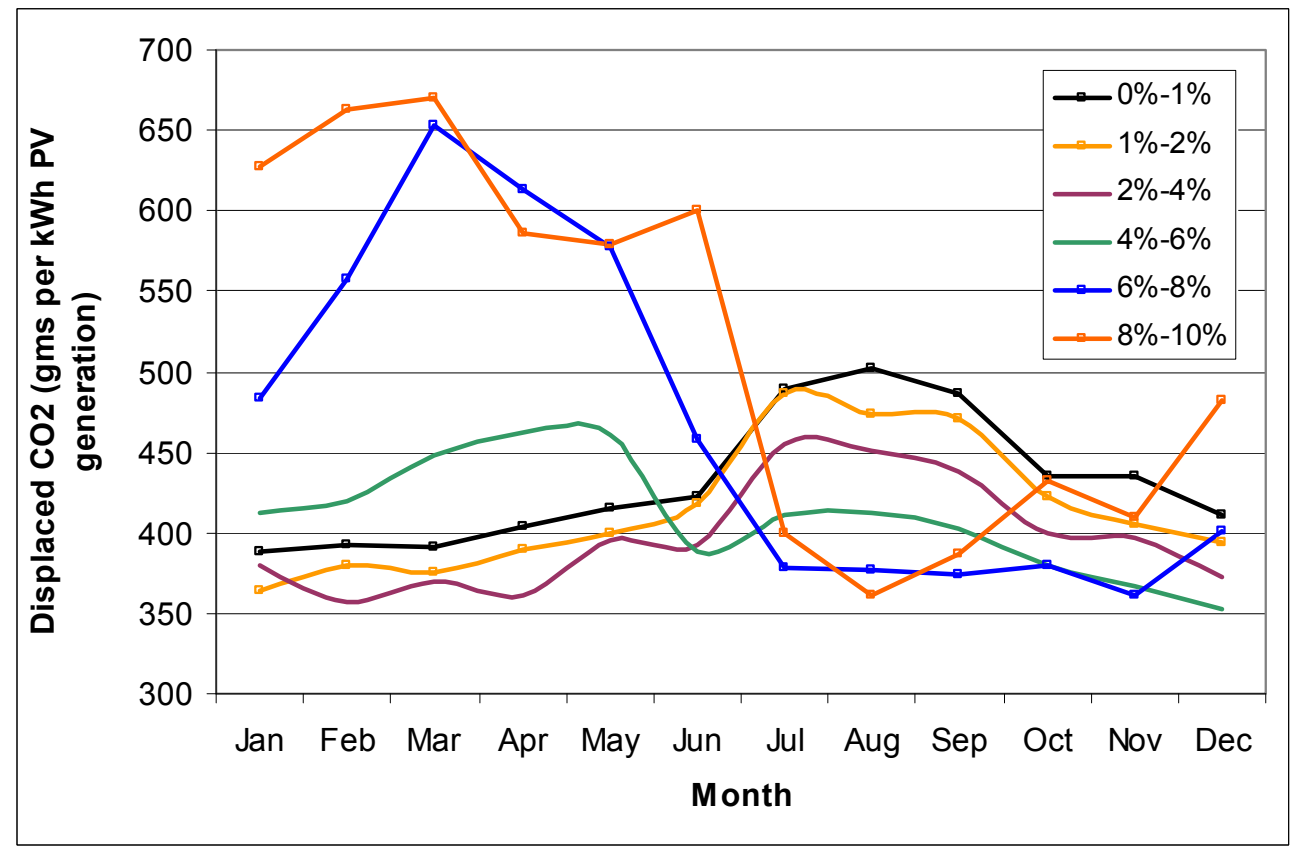

Figure 38. Seasonal Incremental $\mathrm{CO}_{2}$ Emissions Displacement from PV Deployed in WECC 
Figure 39 illustrates the estimated offset rates for $\mathrm{NO}_{\mathrm{x}}$ and $\mathrm{SO}_{2}$ for the entire WECC scenario.

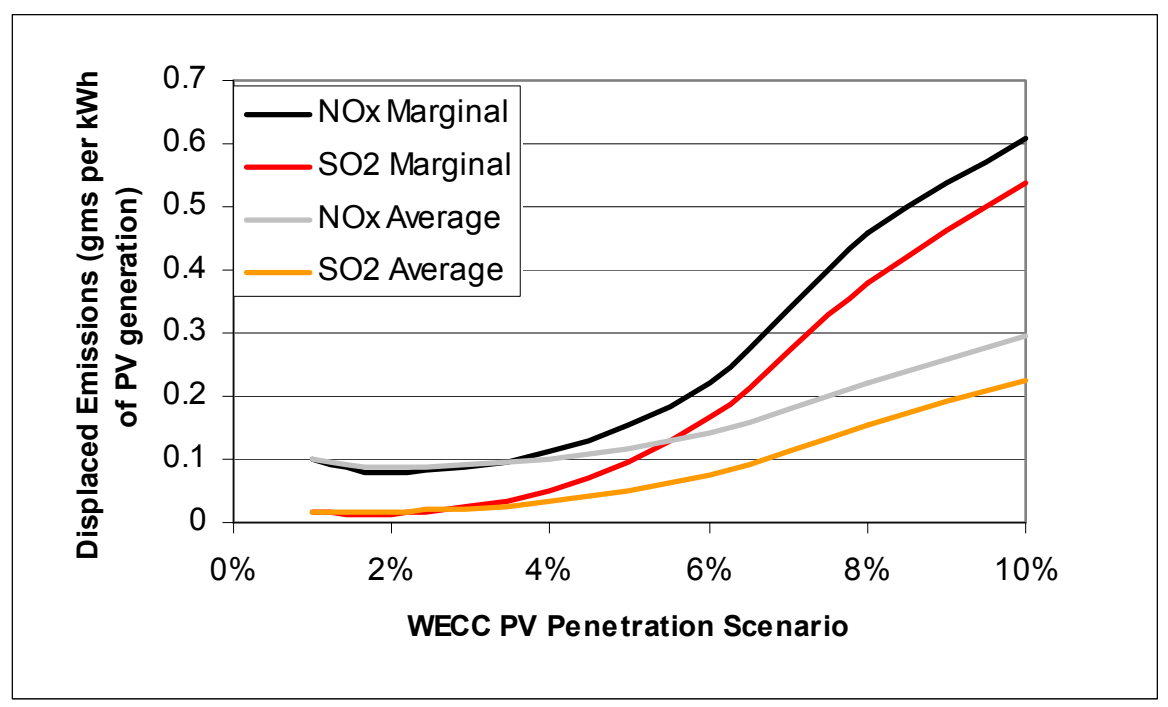

Figure 39. Average and Marginal $\mathrm{NO}_{\mathrm{x}}$ and $\mathrm{SO}_{2}$ Emissions Displacement from PV Deployed in WECC

The seasonal patterns of emissions reductions for $\mathrm{NO}_{\mathrm{x}}$ and $\mathrm{SO}_{2}$ are similar to those for $\mathrm{CO}_{2}$ (as illustrated in Figure 38), because the largest impact on coal generation from PV occurs in the spring and early summer.

\subsection{Future Scenarios}

The results presented in sections 4.3 through 4.5 represent the penetration of PV into the existing grid. Scenarios were also examined using Global Energy's projections of the generation mix in 2015 and 2020. Many of the changes in the grid expected to occur in this time frame, such as the installation of new baseload generation (wind, coal, or geothermal) will have little impact on the marginal generation affected by PV. As a result, the future scenarios are generally similar to the results presented for 2007. Among the most significant differences between the 2007 grid and the 2015 and 2020 grids, as projected in the model, is the greater overall reliance on natural gas, both in combinedcycle and simple-cycle gas turbines, illustrated in Figure 1. In the 2015 and 2020 simulations, this reliance "delays" the offset of coal generation until higher PV penetration is achieved. In addition, the projected future grid also relies more heavily on simple-cycle units. If true, this greater use of less efficient generators would increase the overall benefits of PV generation.

Given the fact that it will take some time for PV to reach the levels of penetration evaluated in this work, the future mix of generator types and their operation in response to intermittent generators, are important considerations. Follow on studies will evaluate a variety of capacity expansion scenarios 


\subsection{Recommendation for Future Research}

Recent analysis and evaluation of wind integration may provide both "lessons learned" and a general path forward for continued evaluation of the impacts of large scale PV deployment into the grid. The analytic questions utilities and the wind industry have been addressing over the last 10 years are similar to the questions that will have to be addressed for PV as this technology penetrates the market. The types of tools and analysis used in wind integration studies are similar to those used in this study; and the solar industry can benefit from the methods that have been developed to understand the impact of stochastic energy resources in electric power systems.

There are many opportunities for research into grid-level impacts of PV. (It should be noted that this list applies only to grid impacts at the generator level. It does not consider any aspects of the many "distributed" benefits or impacts of PV). Important issues for future research include:

- Solar forecasting and Unit Commitment. This study assumes prior knowledge of both load and solar resource. It is unclear how accurately utilities will be able to predict their net load with PV for day-ahead and hour-ahead unit commitment. The cost impacts of forecasting errors and uncertainty on utility operations should be explicitly examined.

- Hydro Dispatchability. The new and different load shapes created by PV deployment will require examination of the capacity of hydro resource to be dispatched to these new patterns.

- Capacity Credit - While there have been a number of analyses of the "capacity credit" of $\mathrm{PV}$, there is significant additional work to be done, especially using the variety of metrics used by individual utilities and system operators. Furthermore, much of the capacity credit analysis has occurred at the hourly time scale. This scale may be too long for utilities to have high levels of confidence in the ability of PV to serve load during peak demand periods. Other potentially important questions related to this topic include: How does the capacity credit change as a function of penetration? How can capacity credit be increased, considering system orientation and spatial diversity? Is the data quality and quantity sufficient to derive dependable capacity credit metrics?

- Peak Demand Day Analysis. PV could be a useful tool for improving air quality on peak demand days. Very detailed examination of PV impacts during theses days should be examined, possibly including sub-hourly analysis to capture actual impacts on peaking generators.

- Combined Technology Studies. It is very important to examine the system impacts of multiple renewable technologies including wind, concentrating solar power, and PV.

- Sub-hourly Impacts. What are the effects of sub-hourly PV ramping? 
- Incorporating T\&D losses. Tools such as PROSYM treat the load at the busbar, and do not consider how variations in load affect T\&D losses.

- Intermittency mitigation techniques Previous wind integration studies have found modest costs at penetrations beyond $20 \%$ (on an energy basis) given sufficient spatial diversity, forecasting ability, and the ability to schedule and commit conventional energy resources over large areas. It is not clear at what levels of penetration PV will be burdened by "excessive" integration costs. Assuming such a level does exist, it may be important to examine enabling technologies and techniques, including increased spatial diversity; diversity of orientation; market-based approaches, such as time-of-use and real-time pricing; and technology options, such as load shifting, long distance transmission, and various centralized and distributed energy storage technologies. Of particular interest may be the use of plug-in hybrid electric vehicles as a PV enabling technology.

- Limitations of Existing Tools. The existing suite of utility simulation tools were designed to examine operations of conventional power stations. In most cases intermittent renewables have been "retrofitted" and there are still limitations in the treatment of technologies such as solar and wind. For example, PROSYM uses a single time zone for the entire WECC region, which may introduce errors when scheduling power flows from PV across the two WECC time zones. Treatment of hydro dispatch and coordination of hydro and thermal generations may also need improvement.

- High Penetration Impacts. In the simulated scenarios, the overall 10\% penetration case created much higher penetration in certain regions in California. The net loads in these regions dropped to a very small fraction of the normal load, which may very well "push the limits" of the model's capabilities. High penetration scenarios require a greater understanding of system boundary conditions, including minimum load levels on existing plants, and hydro limitations. In addition, more transmission load flow studies will be needed to verify the system capabilities assumed in this analysis.

- Sensitivity to PV Location. This study assumes a fixed set of regional penetrations of PV based on existing policies and population patterns. These assumptions are conjectural and it may be useful to examine sensitivity of the results to a variety of PV deployment patterns.

- Impact of Electricity Use Pattern. This study assumes that future electricity use patterns remain the same. This may be unrealistic, given the increased use of time-of-use rates, and the possible use of real-time pricing, both of which could alter load patterns. 


\subsection{Conclusions and Recommendations}

The use of production cost models allows for the estimation of the system impacts of large-scale deployment of PV. Based on a PV deployment scenario in the western United States where PV is mostly utilized in the Southwest and California, the following conclusions are generated:

- At low penetration (less than 4\%), virtually all PV offsets generation from natural gas-fired units, primarily high-efficiency combined-cycle units.

- The natural gas fuel and emissions displacement rate for PV falls as a function of penetration as PV begins to displace more efficient gas units, and also creates increased plant ramping and part load operation.

- Increased penetration of PV (above 4\%) results in greater levels of displaced coal generation, primarily in the high solar output months and low demand period in the late spring.

- At the highest penetration evaluated (10\%) natural gas provides the majority of fuel offset, although the coal offset rate is rising rapidly.

Up to the $10 \%$ penetration case, the net load shapes created by PV appear to fall well within the operational capabilities of the regional grid and the PROSYM model. During a few hours of the year (mid-day in late spring), the net loads created by PV have fallen well below normal load conditions. In this case, PROSYM begins to see conditions close to "minimum load" levels that might require PV curtailment. However, significant additional work is needed to evaluate how well PROSYM characterizes operation of the power system at these very low load levels.

Given the relatively immature state of analysis of the effects of large-scale deployment of $\mathrm{PV}$ on the grid, it is recommended that continued efforts be made to develop appropriate data sets, analysis tools, and techniques. Lessons learned from the wind industry and the tools and methods developed for wind analysis will provide a useful start to this process. 


\subsection{References}

1. Keoleian; Lewis. "Modeling the Life Cycle Energy and Environmental Performance of Amorphous Silicon BIPV Roofing in the U.S.," Renewable Energy, Vol. 28, 2003; pp. 271-293.

2. Berlinski, M. Quantifying Emissions Reductions from New England Offshore Wind Energy Resources. Cambridge, MA: M.S. Thesis. Massachusetts Institute of Technology, 2006.

3. Spiegel, R.J.; Edward, J.; Kern, C.; Greenberg, D.L. "Demonstration of the environmental and demand side management benefits of grid-connected photovoltaic power systems." Solar Energy; Vol.62, No.5; pp 345-58.

4. Spiegel, R.J.; Greenberg, D.L.; Kern, E.C.; House, D.E. "Emissions Reduction Data for Grid-Connected Photovoltaic Power Systems."Solar Energy; Vol. 68, No. 5, 2000; pp. $475-485$.

5. Spiegel, R.J.; Leadbetter; M.R.; Chamu, F. "Distributed grid-connected photovoltaic power system emission offset assessment: statistical test of simulated- and measuredbased data." Solar Energy; Vol. 78 (2005) 717-726

6 Connors, S.; Martin, K.; Adams, M.; Kern, E.; Asiamah-Adjei, B. Emissions Reductions from Solar Photovoltaic (PV) Systems. LFEE Report No.: 2004-003 RP August 2004.

7. Denholm, P.; Margolis, R.M. "Evaluating the Limits of Solar Photovoltaics (PV) in Traditional Electric Power Systems." Energy Policy; Vol.35, 2007; pp. 2852-2861.

8. Global Energy Decisions. PROSYM User Guide. Software Version 5.5 June 2007

9. California Independent System Operator. California ISO 2007 Summer Loads and Resources Operations Assessment, March 2007

10. National Renewable Energy Laboratory, National Solar Radiation Database 19912005 Update: User's Manual NREL/TP-581-41364, http://rredc.nrel.gov/solar/old_data/nsrdb/1991-2005/. 


\section{REPORT DOCUMENTATION PAGE}

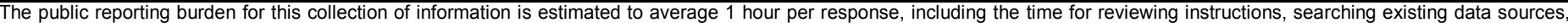

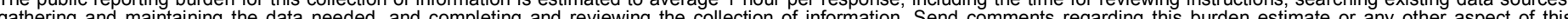

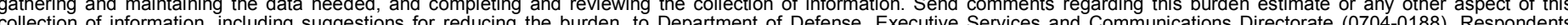

should be aware that notwithstanding any other provision of law, no person shall be subject to any penalty for failing the

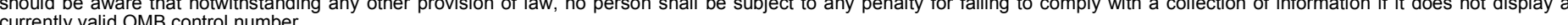

PLEASE DO NOT RETURN YOUR FORM TO THE ABOVE ORGANIZATION.

\begin{tabular}{l|l|l|l} 
1. REPORT DATE $(D D-M M-Y Y Y Y)$ & 2. REPORT TYPE & 3. DATES COVERED (FrOm - TO)
\end{tabular}

February 2008

Technical report

4. TITLE AND SUBTITLE

Production Cost Modeling for High Levels of Photovoltaics

Penetration

5a. CONTRACT NUMBER

DE-AC36-99-G010337

5b. GRANT NUMBER

5c. PROGRAM ELEMENT NUMBER

6. AUTHOR(S)

P. Denholm, R. Margolis, and J. Milford

5d. PROJECT NUMBER

NREL/TP-581-42305

5e. TASK NUMBER

PVB7.6401

5f. WORK UNIT NUMBER
7. PERFORMING ORGANIZATION NAME(S) AND ADDRESS(ES)

National Renewable Energy Laboratory

1617 Cole Blvd.

Golden, CO 80401-3393
8. PERFORMING ORGANIZATION REPORT NUMBER

NREL/TP-581-42305

9. SPONSORING/MONITORING AGENCY NAME(S) AND ADDRESS(ES)

10. SPONSOR/MONITOR'S ACRONYM(S) NREL

11. SPONSORING/MONITORING AGENCY REPORT NUMBER

12. DISTRIBUTION AVAILABILITY STATEMENT

National Technical Information Service

U.S. Department of Commerce

5285 Port Royal Road

Springfield, VA 22161

13. SUPPLEMENTARY NOTES

14. ABSTRACT (Maximum 200 Words)

The goal of this report is to evaluate the likely avoided generation, fuels, and emissions resulting from photovoltaics (PV) deployment in several U.S. locations and identify new tools, methods, and analysis to improve understanding of $\mathrm{PV}$ impacts at the grid level.

15. SUBJECT TERMS

production cost model; grid integration; system dispatch; avoided emission; photovoltaics; PV; National Renewable Energy Laboratory; NREL

\begin{tabular}{|c|c|c|c|c|}
\hline \multicolumn{3}{|c|}{ 16. SECURITY CLASSIFICATION OF: } & \multirow{2}{*}{$\begin{array}{l}\text { 17. LIMITATION } \\
\text { OF ABSTRACT } \\
\text { UL }\end{array}$} & \multirow{2}{*}{$\begin{array}{l}\text { 18. NUMBER } \\
\text { OF PAGES }\end{array}$} \\
\hline $\begin{array}{l}\text { a. REPORT } \\
\text { Unclassified }\end{array}$ & $\begin{array}{l}\text { b. ABSTRACT } \\
\text { Unclassified }\end{array}$ & $\begin{array}{l}\text { c. THIS PAGE } \\
\text { Unclassified }\end{array}$ & & \\
\hline
\end{tabular}

19a. NAME OF RESPONSIBLE PERSON

19b. TELEPHONE NUMBER (Include area code) 